\title{
Multi-Objective Optimization of Deep Groove Ball Bearings Using Fatigue-Wear-Thermal Considerations Through Genetic Algorithms
}

\author{
Raghavendra Rohit Dabbara \\ Indian Institute of Technology Guwahati \\ Rajiv Tiwari ( $\nabla$ rtiwari@iitg.ernet.in ) \\ Indian Institute of Technology Guwahati https://orcid.org/0000-0003-2111-5918
}

\section{Original Article}

Keywords: Ball Bearings (BB), Optimal Design, Multi-objective Optimization, Elitist Non-dominated Sorting Genetic Algorithm-II (NSGA-II), Sensitivity Analysis.

Posted Date: November 17th, 2021

DOI: https://doi.org/10.21203/rs.3.rs-1073275/v1

License: (c) (1) This work is licensed under a Creative Commons Attribution 4.0 International License.

Read Full License 


\title{
Multi-Objective Optimization of Deep Groove Ball Bearings using Fatigue-Wear-Thermal Considerations through Genetic Algorithms
}

\author{
Raghavendra Rohit Dabbara ${ }^{1}$ and Rajiv Tiwari ${ }^{2 *}$ \\ ${ }^{1}$ Graduate Student, Department of Mechanical Engineering, Indian Institute of Technology Guwahati, \\ Guwahati, Assam, 781039, India, rohit.dabbara@gmail.com \\ ${ }^{2}$ Professor, Department of Mechanical Engineering, Indian Institute of Technology Guwahati, \\ Guwahati, Assam, 781039, India, rtiwari@iitg.ernet.in
}

\begin{abstract}
Bearings are the key components in a wide range of machines used in different sectors of industries. Consequently, any improvement in the performance of bearings would be a step forward to extract better performance from those machines. With this motivation in mind, we selected the most common type of bearing, the Deep Groove Ball Bearing (DGBB), for optimizing its performance. Obviously, the first and foremost performance characteristic would be the dynamic load carrying capacity $\left(C_{D}\right)$, whose improvement directly leads to the increased service life of the bearing. We have considered two more characteristics of bearings, which we thought would have an impact on the bearings' performance. They are elasto-hydrodynamic film thickness $\left(h_{m i n}\right)$ and maximum temperature developed $\left(T_{\max }\right)$ inside the bearing. Maximization of the lubricant thickness decreases the damage to the rolling elements and the raceways due to metal-metal contact. And minimization of temperature is desirable in every machine element. Later, we would also see that the three objective functions chosen are conflicting in nature and hence mutually independent. For the current optimization problem, a genetic algorithm, Elitist Non-dominating Sorting Genetic Algorithm (NSGA-II) is chosen. And the bearing dimensions, which could be controlled during manufacturing are chosen as the design variables. Multiple constraints are chosen based on the design space and strength considerations. The optimization algorithm is used on a set of commercially available bearings. Pareto fronts are drawn to give the designer a multitude of optimal solutions to choose from. However, in this paper, the kneepoint solution is presented, which is one of the optimum solutions. When compared with the commercial bearings, the bearings with optimized dimensions have higher dynamic load carrying capacities and hence longer life. Also, the sensitivity analysis is done to check the robustness of the bearings to manufacturing tolerances in the design variables. Finally, for visualization and as a check for physical plausibility, the radial dimensions of one of the optimized bearings have been shown.

Keywords: Ball Bearings (BB); Optimal Design; Multi-objective Optimization; Elitist Non-dominated Sorting Genetic Algorithm-II (NSGA-II); Sensitivity Analysis.
\end{abstract}

\section{Introduction}

Ball bearings (BB) are primarily employed to carry radial loads and are also capable of carrying a certain amount of axial loads. These are used to carry small loads, unlike roller bearings. Axial load capacities of these bearings are affected by their diametral clearances. Increased diametral clearances enable these bearings to carry heavier axial loads. The internal structure of these bearings is very simple. By comparing with other types of bearings, it is easy to mass produce with high grade of accuracy. For assembling these bearings, the inner ring is moved to an eccentric position relative to the outer ring. A certain amount of balls is filled and the size and number of balls are limited by the assembly angle. Then the inner ring can be slightly pressed and shifted to the concentric position with the outer ring. The balls are mostly made of steel. In order to reduce centrifugal forces of balls at high speed, hollow balls welded from half balls are developed. These are found in a variety of applications such as in bicycles, dental and medical appliances, aerospace equipment, flowmeters, ovens, environmental systems, gearboxes, electric motors, household electric appliances, internal combustion engines, and agricultural machinery. These ever-increasing applications demand bearings with longer

\footnotetext{
* Corresponding author: rtiwari@iitg.ernet.in
} 
lives and reliability and have encouraged researches towards improving the design of bearings for optimum performance.

Optimization is a stage in design process which allows the engineer to locate the optimum solution by following a systematic process using a set of design constraints and criteria. Every machine element can be optimized relative to its present design for better performance and bearings are no exception. In this paper, an attempt has been made, successfully, to optimize the performance of commercially available bearings by changing their internal dimensions keeping the outer dimensions intact.

The design and analysis of machine elements has always been a lucrative field of study for a lot of researchers but surprisingly not much literature is found on optimization of ball bearings even though they are important components in many machines. Changsen (1991) gives a clear and logical explanations regarding analytical methods of rolling bearings. He gave descriptions of geometry, kinematics, load distribution, stress and deformation, calculation of dynamic load rating and elastohydrodynamic lubrication. His work also gave insight to optimization of design and computer aided design of rolling bearings. Harris and Kotzalas (2006) text spans many scientific disciplines starting from bearing types, geometry, elasticity, statics and dynamics to lubrication, load distribution and heat transfer in bearings. Also, the basic study of bearings is done from this text. Harris and Barnsby (1998) put forward an algorithm to find the temperatures at various points in a bearing accurately. Seireg (1972) used optimization techniques to design some commonly used machine elements such as journal bearings, gears, pressure vessels under various types of loading such as bending, torsional loading and problems involving elastic contact and distributed loading. Andreason (1973) proposed the formulation required for the calculation of bearing load in tapered roller bearings which also took the shaft misalignment, initial preload into consideration. Parker and Singer (1978) determined the bearing heat generation and temperature as a function of shaft speed, radial and thrust loads, lubricant flow and lubricant inlet temperature. Jamison et al. (1977) discussed the effects of tolerance control in manufacturing and wear at rib-roller contact under poor lubricating conditions on bearing performance. Peng et al. (2012) has performed numerical calculations on elasto-hydrodynamic lubrication of grease lubricated ball bearing and concluded that the inner ring experiences more wear when compared with outer ring. Kreith et al. (2012) presented the equations for convective heat transfer coefficient for rotating cylinder for free and forced convection. Kendoush (1996) presented an approximate solution for convective heat transfer rates through a laminar boundary layer over a rotating circular cylinder in still air. The solution has a good correlation with the measured data.

Many optimization methods have been developed and some of them have been studied (Zitzler, 1999; Deb, 2012) to select the best available algorithm to solve the multi-objective optimization problem. Some of the available algorithms are Artificial Bee Colony (ABC) algorithm, Strength Pareto Evolutionary Algorithm (SPEA), Particle Swarm Optimization (PSO) etc. A comprehensive study has been made on these algorithms and NSGA-II is taken as the optimization algorithm for the current problem. Deb (2001) developed the NSGA-II algorithm, which is being used in the current work. In this paper, he has introduced NSGA-II, various limitations overcome by it and its advantages over existing optimization methods. He has proved that by taking five test simulations. Also, he introduced the crowded comparison operator, which is used while assigning ranks to the population. Deb et al. (2002) discussed a new modified multi-objective evolutionary algorithm, which focuses on a smaller number of potentially more interesting solutions, called knee solutions, since these are more relevant to the decision maker and two methods have been proposed to achieve this along with a good number of test cases.

Chakraborty et al. (2003) explained a method to optimize ball bearings using genetic algorithms. Longest fatigue life is taken as the objective function with five design parameters. Rao and Tiwari (2007) presented the formulation and procedure for solving the constrained non-linear optimization problem, i.e. design of roller bearings with longer fatigue life as objective function. A study has been made on the range of design constraint constants and they have been given ranges based on the maximum dynamic capacity. Kumar et al. (2008) solved the non-linear optimization problem under design and strength constraints for cylindrical roller bearings for the maximum fatigue life using the real-coded genetic algorithm. They also performed sensitivity analysis to see the effect of changes in design parameters on the bearing performance. They also put forward an idea to select elasto-hydrodynamic minimum film thickness as an objective function. Tiwari et al. (2012) developed 
an optimum design methodology for tapered roller bearings to increase the fatigue life. It has been optimized by using a constrained nonlinear formulation with real-coded genetic algorithms. Tiwari and Chandran (2015) developed an optimization algorithm for tapered roller bearings, cylindrical roller bearings, and ball bearings for three objective functions, sequentially, which are the dynamic capacity, elastohydrodynamic minimum film-thickness, and maximum bearing temperature, respectively. Optimization has been performed using Artificial Bee Colony (ABC) algorithm along with convergence study and sensitivity analysis. Kalyan and Tiwari (2016) presented an optimization for the objective functions taken in the study but for needle roller bearings, as both single and simultaneous optimizations using NSGA-II. Jat and Tiwari $(2018,2020)$ optimized spherical roller bearings for multiple objectives using NSGA-II, also performed the sensitivity analysis and comparison with standard catalogue bearings. Kalyan et al. (2020) optimized the tapered roller bearings for improved fatigue, wear and thermal characteristics. They have used NSGA-II as the optimization algorithm and have chosen the solution closer to the knee point as the optimum design. Verma and Tiwari (2020) optimized the fatigue life of tapered roller bearings considering effect on fatigue life due to the uncertainties during manufacturing as an objective function. This inclusion lead to the robust design and the formulation presented could be applied in the optimization of any machine component, which have significant uncertainties in their material as well as manufacturing parameters.

The research done till now by various authors discussed above has made design recommendations based on the dynamic capacity of the bearings and lubricant thickness but there is another important factor which plays a key role in bearing performance, i.e. the thermal effect. While operating at very high speeds, there will be a significant amount of heat generation that leads to an increase in operating temperatures. While the structural parts, which are made of metal, may remain unaffected (expect of expansion) with this magnitude of heat generation, the thermal effect on lubricant is more profound. At high temperatures, it is more likely that lubricant will deteriorate which leads to, but not restricted to, metal to metal contact while operating. This leads to increased wear and release of harmful gases which are likely to be harmful to humans as well as the environment.

To address this, the present research work is done taking thermal effects also into consideration by taking the temperature developed as an objective (minimization) function. The formulation also takes the material properties of lubricant as a function of temperature. Further, the formulation in this paper allows the designer to optimize the bearing for the maximum temperature with variable lubricant flow rates. This is particularly advantageous while designing bearings for space applications, where the lubricant quantity is limited, and designing by roping in this constraint is advantageous. Further research can be carried out with this as the starting point (variation in performance with lubricant flow rate). Also, to prove that NSGA-II has a better search space, and hence gives better solutions, than the previously used ABC algorithm (Tiwari and Chandran, 2015), life comparison factors have been calculated.

Hence, in the current study, for deep groove ball bearings, a constraint nonlinear optimization problem formulated and solved using NSGA-II algorithm with dynamic capacity $\left(C_{D}\right)$, maximum bearing temperature $\left(T_{\max }\right)$, and EHL minimum film thickness $\left(h_{\min }\right)$ as objectives, which have been optimized individually and simultaneously. The bearings optimized are the standard bearings available in the market and the input parameters are taken from available bearing catalogs. To ensure that the simulation does not stop at a local optimum, a convergence study is performed and a sensitivity analysis is done to see the robustness of the design with small changes in design parameters.

\section{Geometrical aspects}

The bearing geometry is defined by its outer or boundary dimensions, bore diameter $(d)$, outer diameter $(D)$, and width of bearing $\left(B_{w}\right)$. For a specific set of outer dimensions, the parameters required to define the internal geometry are the diameter of the ball $\left(D_{b}\right)$, the pitch diameter $\left(D_{m}\right)$, the inner raceway, and outer raceway curvature coefficients $\left(f_{i}\right.$ and $\left.f_{o}\right)$, and the number of balls $(Z)$. A cross-sectional view of a deep groove ball bearing is depicted in Fig 1. 

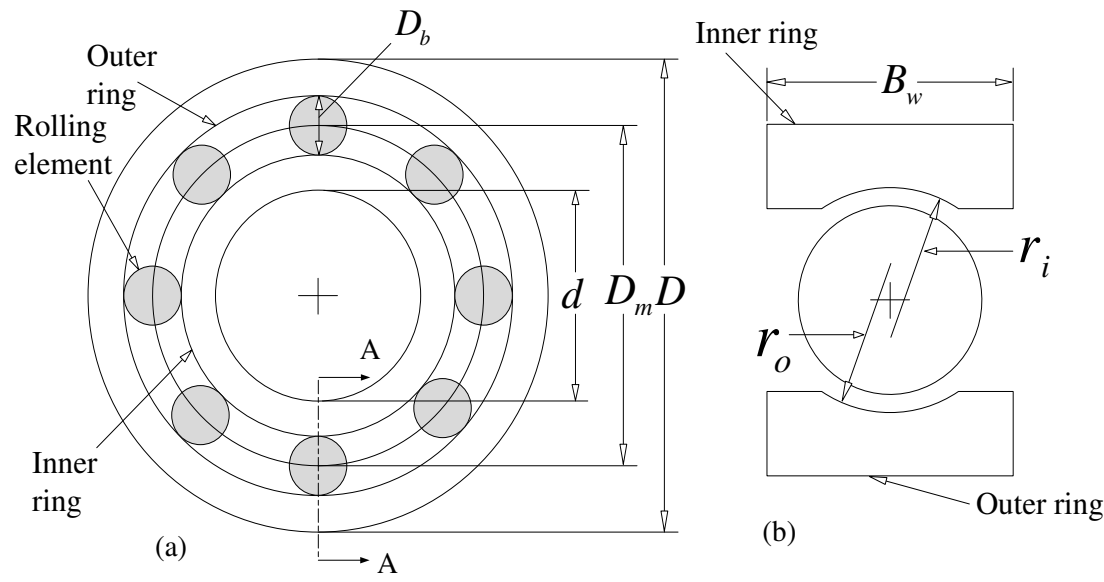

(b)

Fig. 1. (a) Bearing cross-sectional geometry (b) A cut section

\section{Representation of optimization problem}

Any multi-objective optimization problem can be viewed as three parts namely,
Objectives:
Minimize/Maximize
$f_{m}(\mathbf{x}) \quad m=1,2, \ldots, M$
Constraints:
Subject to
$\mathrm{g}_{j}(\mathbf{x}) \geq 0$
$j=1,2, \ldots, J$
$h_{k}(\mathbf{x})=0 \quad k=1,2, \ldots, K$
Variable Bounds:
$x_{l}^{(L)} \leq x_{l} \leq x_{l}^{(U)}$,
$x_{l} \in \mathbf{x}$
$l=1,2, \ldots, L$

The problem statement contains $m$ number of objective functions, which have to be optimized with a solution vector $\mathbf{x}$ containing $n$ number of decision variables

$$
\boldsymbol{x}=\left\{\begin{array}{llll}
x_{1} & x_{2} & \ldots & x_{n}
\end{array}\right\}^{\mathrm{T}}
$$

each of these variables $x_{i}$ is constrained by a lower bound as well as an upper bound. The geometric parameters of standard bearings are varied to get optimized results.

\subsection{Problem Formulation for Deep Groove Ball Bearings}

\subsubsection{Design Variables}

These are mutually independent variables which are to be calculated through optimization and the design parameter vector used for optimizing ball bearing is

$$
\mathbf{x}=\left\{D_{m}, D_{b}, Z, f_{i}, f_{o}, K_{D \min }, K_{D \max }, \varepsilon, e, \zeta\right\}^{\mathrm{T}}
$$

Here,

$$
f_{i}=r_{i} / D_{b} ; \quad f_{o}=r_{o} / D_{b}
$$

Parameters used to define the internal geometry of bearing are $D_{m}, D_{b}, Z, f_{i}$, and $f_{o}$ whereas the other parameters are $K_{D \min }, K_{D \max }, \varepsilon, e$, and $\zeta$ are part of constraints and do not directly represent any measurement of bearing geometries. Also assembly angle ( $\left.\phi_{o}\right)$ (Fig. 2) is an important geometrical constraint. Based on the geometry, one would arrive at the following expression for the same

$$
\phi_{o}=2 \pi-2 \cos ^{-1} \frac{\left[\{(D-d) / 2-3(T / 4)\}^{2}+\left\{D / 2-(T / 4)-D_{b}\right\}^{2}-\{d / 2+(T / 4)\}^{2}\right]}{2\{(D-d) / 2-3(T / 4)\}\left\{D / 2-(T / 4)-D_{b}\right\}},
$$

with $T=D-d-2 D_{b}$ 


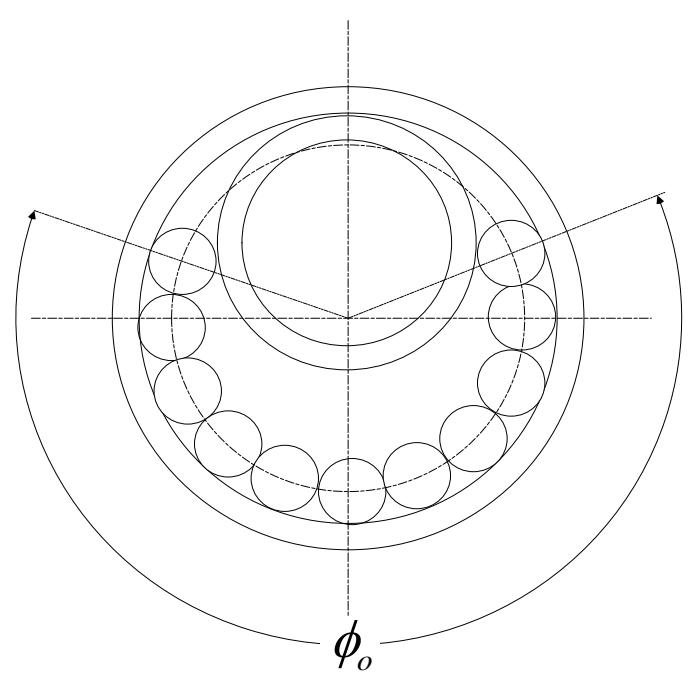

Fig. 2. Assembly angle

\subsubsection{Objective functions}

The bearing performance values that need to be optimized for either maximum or minimum are termed as the objective functions. Either problem can be converted into the other by " $-f(\mathbf{x})$ " or " $1 / f(\mathbf{x})$ ". This is termed as the duality principle. It is very useful since in most of the engineering applications of optimization, multiple objectives need to be optimized simultaneously.

Maximization of fatigue life is the basic and important factor for designing any bearing. To achieve this, the dynamic load carrying capacity should be higher. So, it is selected as one of the objective. Experiments indicate that if a bearing works with a sufficient EHL, its fatigue life will increase significantly. So, maximizing the thickness of EHL has been taken as the second objective. Temperature rise in a bearing is attributed to the frictional heat generation and must be dissipated. If the heat generated is not dissipated accordingly, an unsteady state condition arises, which leads to rise in system temperature. That leads to the lubricant deterioration and ultimately resulting in the bearing failure. In some applications, external cooling methods may be deployed but in applications where it is not possible, it is advantageous to analytically determine the thermal conditions of bearing operation. It has been found that the dimensions of bearing have an effect on the temperature developed and hence the minimization of maximum temperature developed is selected as the third objective.

Hence, we have three objectives for simultaneous optimization, the dynamic capacity $\left(C_{d}\right)$, the minimum film thickness $\left(h_{\min }\right)$, and bearing temperature $\left(T_{\max }\right)$. The first two objective functions have to be maximized while the bearing temperature has to be minimized.

\subsubsection{Dynamic capacity $\left(C_{d}\right)$}

The expression for dynamic capacity for the deep groove ball bearings is given as

$$
C_{d}=\left\{\begin{array}{lc}
f_{c} Z^{2 / 3} D_{b}^{1.8} & D_{b} \leq 25.4 \mathrm{~mm} \\
3.647 f_{c} Z^{2 / 3} D_{b}^{1.4} & D_{b}>25.4 \mathrm{~mm}
\end{array}\right.
$$

where,

$$
f_{c}=37.91\left[1+\left\{1.04\left(\frac{1-\gamma}{1+\gamma}\right)^{1.72}\left(\frac{f_{i}\left(2 f_{o}-1\right)}{f_{o}\left(2 f_{i}-1\right)}\right)^{0.41}\right\}^{10 / 3}\right]^{-0.3}\left[\frac{\gamma^{0.3}(1-\gamma)^{1.39}}{(1+\gamma)^{1 / 3}}\right]\left[\frac{2 f_{i}}{2 f_{i}-1}\right]^{0.41}
$$

Where $\gamma$ not being an independent parameter. The bearing considered presently has the contact angle $\alpha$ equal to zero, therefore $\gamma=D_{b} / D_{m}$. The objective function is maximization of $C_{d}$ and is expressed as,

$$
\max [f(X)]=\max \left[C_{d}\right]
$$




\subsubsection{Elasto-hydrodynamic minimum film thickness $\left(\boldsymbol{h}_{\min }\right)$}

Elasto-hydrodynamic lubrication (EHL) theory is employed in the calculation of lubricant film thickness developed at the rolling element and raceway contacts. The $h_{\min }$ is calculated separately for inner raceway and outer raceway; so that, while optimizing, the minimum of the two can be maximized. Hence, in equation (13) the values of inner/outer ring should be substituted separately. Thus, the complete objective function for $h_{\min }$ can be expressed as,

$$
\begin{gathered}
h_{\text {min, }, \text { ing }}=3.63 a_{1}^{0.49} R_{x, \text { ring }}^{0.466} E_{o}^{-0.117} Q^{-0.073}\left\{\frac{\pi n_{i} D_{m} \eta_{o}\left(1-\gamma^{2}\right)}{120}\right\}^{0.68}\left[1-\exp \left\{-0.703\left(\frac{R_{(y, \text { ring })}}{R_{(x, \text { ring })}}\right)^{0.636}\right\}\right] \\
h_{\text {min }}=\min \left(h_{\text {min, inner }}, h_{\text {min }, \text { outer }}\right)
\end{gathered}
$$

Terms used in the above formula are given below

$$
\begin{gathered}
Q_{i, o}=\frac{5 F_{r}}{i Z \cos \alpha} \\
R_{(x, i)}=\frac{D_{b}}{2(1-\gamma)} ; \quad R_{(y, i)}=\frac{f_{i} D_{b}}{2 f_{i}-1} \\
R_{(x,)}=\frac{D_{b}}{2(1+\gamma)} ; \quad R_{(y, o)}=\frac{f_{o} D_{b}}{2 f_{o}-1}
\end{gathered}
$$

Here, the maximization of $h_{\min }$ is one of the objectives and hence is expressed as

$$
\max [f(X)]=\max \left[h_{\min }\right]
$$

\subsubsection{Maximum Bearing Temperature $\left(T_{\max }\right)$}

The maximum temperature inside the bearing is found by solving two sets of simultaneous equations. For deriving the first set of equations (Table 1), various points or nodes are selected throughout the bearing (Fig 3) and heat balance equations are written at each node. The temperature at each node is effected by the temperatures of the surrounding nodes. Eight nodes are considered for BB in the present case (Fig 3). The figure shows the bearing assemble system consists of ball bearing, housing and shaft. The bearing assembly is lubricated. The housing is mounted with the outer ring. In this, eight temperatures, $T_{1}, T_{2}, T_{3}, T_{4}, T_{5}, T_{6}, T_{7}$, and $T_{8}$, are related to different nodes on the bearing and $T_{A}$ is the ambient temperature. For deriving the second set of equations (Table 2), six nodes are selected at the rolling element-lubricant-raceway ring contact points for the inner and outer raceways (Fig 4) and heat balance equations are written at each node. These equations have been derived from basic heat transfer concepts and hence a detailed explanation is not given. However, they have been explained in detail in (Tiwari and Chandran, 2015). In Table $1, h_{r}$ is the radiation heat transfer coefficient, $\mathcal{E}$ denotes thermal emissivity, $l$ gives distance between two points $(i, j)$ involved in the heat transfer, $A$ is the area normal to the heat flow in $\mathrm{m}^{2}, T_{i}$ and $T_{j}$ are temperatures at two points $(i, j)$ between which heat transfer occurs, $\bar{\omega}$ is the bearing width, $r_{o}$ denotes outer radius, $r_{i}$ denotes inner radius, $t$ is thickness of the seal. The nodal temperatures obtained by solving the first set of equations (table 1 ) give a rough estimate of the temperatures developed. The lubricant temperature obtained in the first estimation is used as the inlet lubricant temperature in second. For accurate estimation of the maximum temperature, the second set of equations are solved, which gives the temperatures at ball-raceway contact points. The lubricant temperature at different nodes (refer Fig. 7) has been obtained by solving the system of linear equations, which are presented in table 2 .

The objective is to get a minimum temperature and is expressed by the equation,

$$
\min [f(X)]=\min \left[T_{\max }\right]
$$




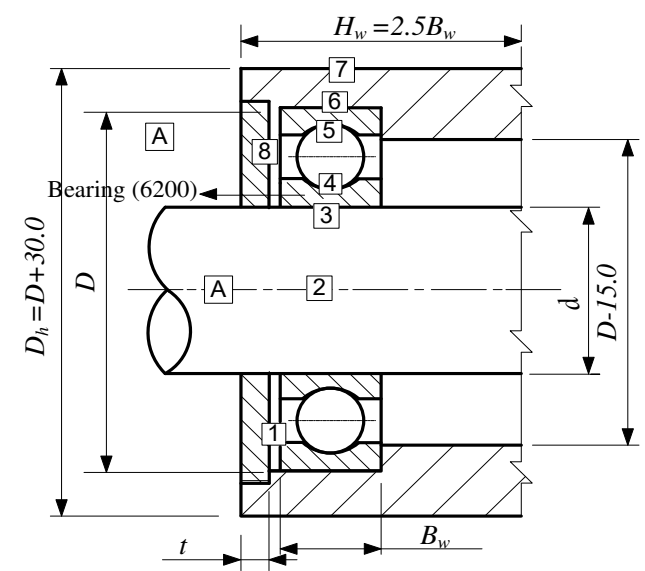

Fig. 3. Temperature node systems along with housing and bearing for ball bearing.

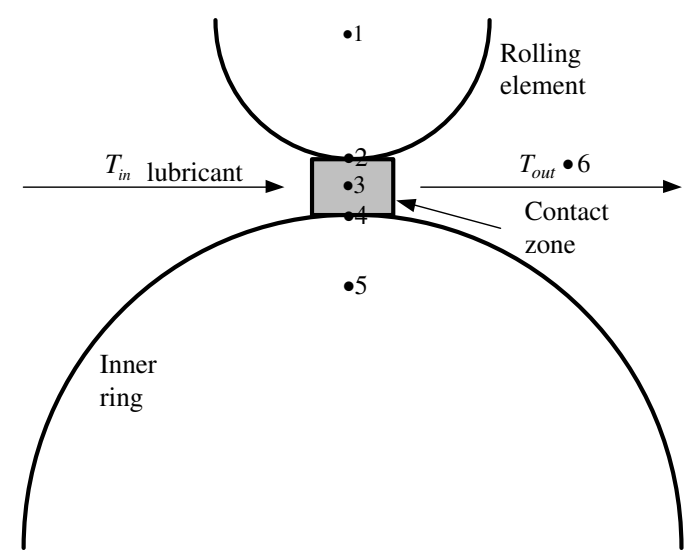

Fig. 4. Ball-lubricant-inner raceway temperature node system 
Table 1: Thermal equilibrium equations for the housing and bearing.

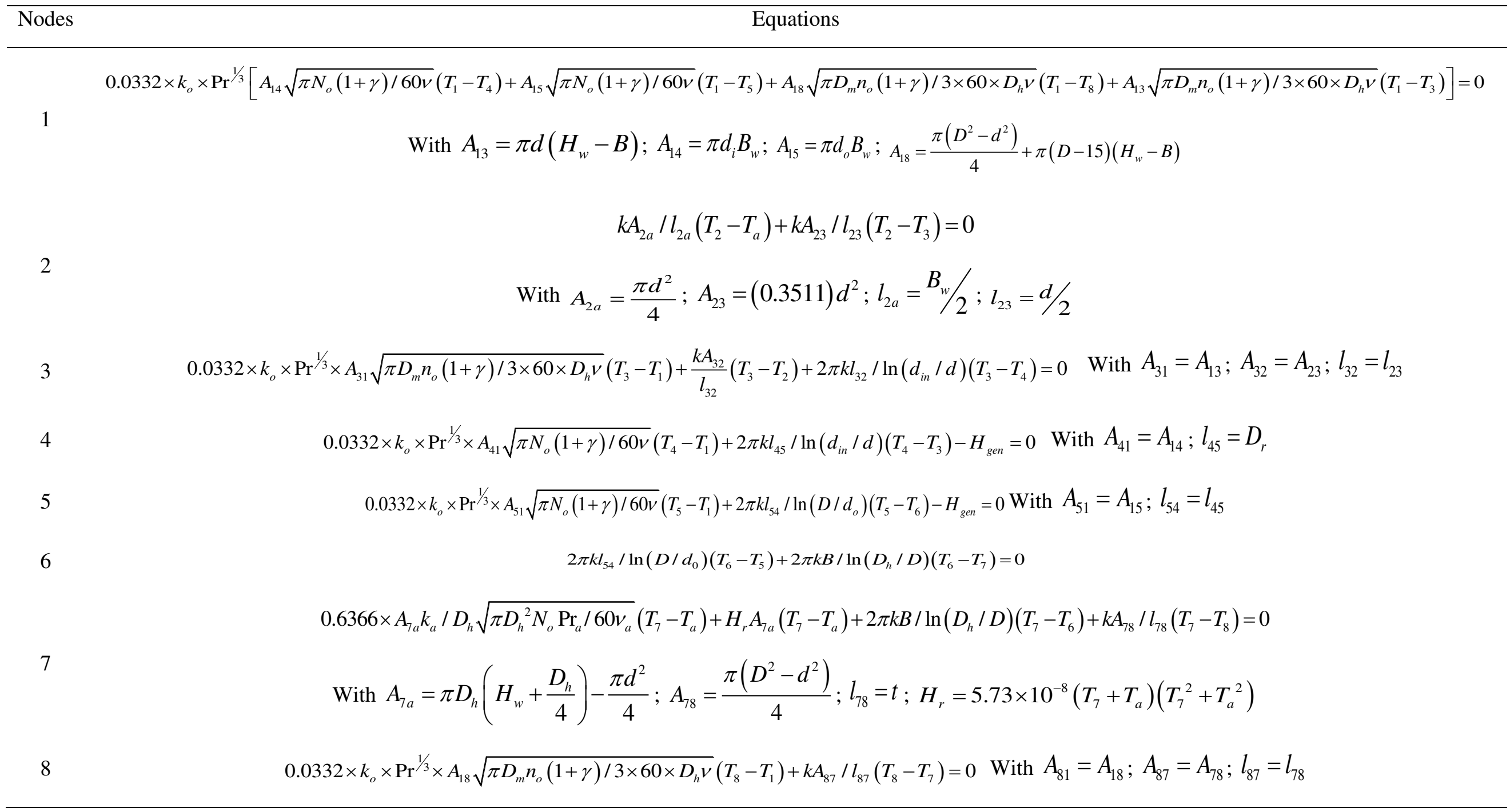


Table 2: Thermal equilibrium equations at the contact of inner raceway and ball.

\begin{tabular}{|c|c|}
\hline Nodes & Equations \\
\hline 1 & Where $A_{12}=0.3511 D_{r}^{2}, A_{16}=\pi D_{r}^{2} / 4, l_{12}=D_{r} / 2$ \\
\hline 2 & 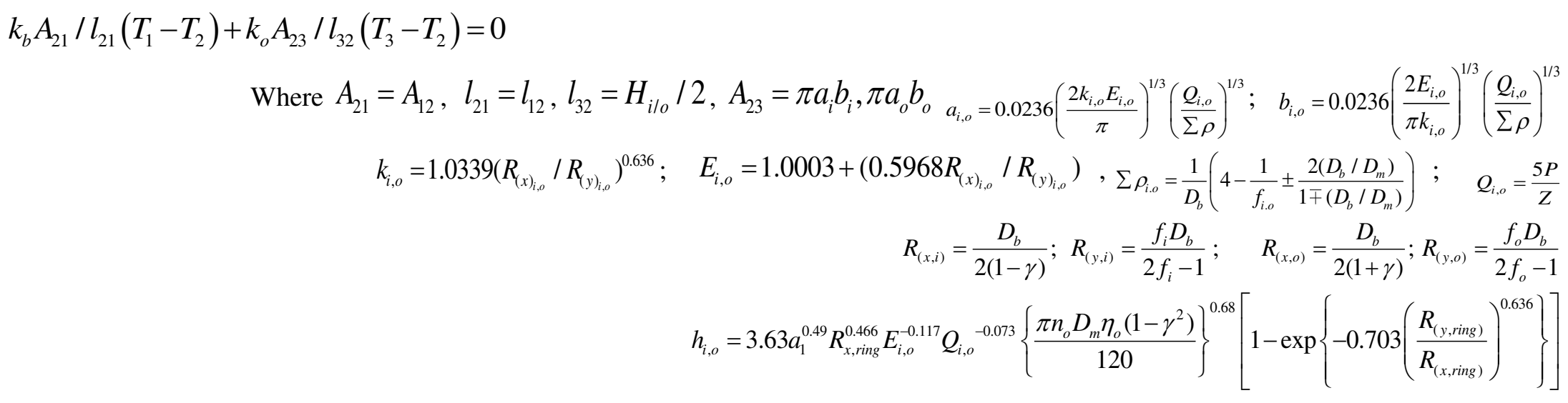 \\
\hline 3 & $k_{o} A_{23} / l_{23}\left(T_{2}-T_{3}\right)+k_{o} A_{43} / l_{43}\left(T_{4}-T_{3}\right)+H_{g e n}-w C_{p}\left(T_{6}-T_{i n}\right)=0 ; \quad$ Where $A_{32}=A_{23}, A_{43}=A_{23}, l_{23}=l_{32}, l_{43}=l_{23}$ \\
\hline 4 & $\begin{array}{r}\text { Where } A_{34}=A_{32}, A_{54}=\theta B \sqrt{\left(r_{o}^{2}+r_{i}^{2}+r_{i} r_{o}\right) / 3}, l_{54, i}=\left(d_{i}-d\right) / 4, \\
l_{54, \mathrm{o}}=\left(D-d_{o} / 4\right), r_{i . i}=\left(d_{i}+d\right) / 4, r_{o, i}=d_{i} / 2 ; r_{i . \mathrm{o}}=\left(d_{o}+D\right) / 4, r_{o, \mathrm{o}}=d_{o} / 2\end{array}$ \\
\hline 5 & Where $A_{45}=A_{54}, A_{65}=\pi d_{i, o} B / 2 Z, l_{45}=l_{54}$ \\
\hline 6 & $h_{v 16} A_{16}\left(T_{1}-T_{6}\right)+h_{v 56} A_{56}\left(T_{5}-T_{6}\right)+w C_{p}\left(T_{i n}-T_{6}\right)=0$ \\
\hline
\end{tabular}




\subsubsection{Constraints}

Constraints provide a feasible region for design parameters and through optimization we arrive at values of design parameters so that we arrive at the maximum/minimum value for the objective function. Nine constraints are selected for the present optimization problem and explained below:

Constraint 1 gives an intuitive maximum limit for the number of rolling elements (balls) in a given bearing from the fact the assembly angle is positive. Constraints 2 and 3 give an upper and lower bound through unknown constants $K_{D \min }$ and $K_{D \max }$, whose values are determined at the end of each run. Constraint 4 is an additional constraint, which limits the ball diameter based on the bearing width. Constraints 5 and 6 ensure the running mobility of bearing by making the difference between the pitch diameter and the average diameter less than a specified value. Constraint 7 limits the minimum thickness of the outer ring at raceway bottom from the strength consideration of the outer ring. Constraints 8 and 9 ensure that the balls roll freely on the raceways without interference by maintaining a minimum curvature of radius at both the raceways. The constraint equations of all the above constraints are given in Table 3 and Table 4.

Table 3: Constraints to define the feasible space of geometric variables.

\begin{tabular}{ccc}
\hline $\begin{array}{c}\text { Constraint } \\
\text { Number }\end{array}$ & Range of Variable & Constraints \\
\hline 2 and 3 & $K_{D \text { min }}(D-d) \leq 2 D_{b} \leq K_{D \text { max }}(D-d)$ & $g_{2}(X)=2 D_{b}-K_{D \text { min }}(D-d) \geq 0$ \\
& & $g_{3}(X)=K_{D \text { max }}(D-d)-2 D_{b} \geq 0$ \\
8 and 9 & $f_{i} \geq 0.515$ & $g_{8}(X)=f_{i} \geq 0.515$ \\
& $f_{o} \geq 0.515$ & $g_{9}(X)=f_{o} \geq 0.515$ \\
\hline
\end{tabular}

Table 4: Design constraints.

\begin{tabular}{cc}
\hline Constraint number & Constraint \\
\hline & $g_{1}(X)=\frac{\phi_{0}}{2 \sin ^{-1}\left(D_{b} / D_{m}\right)}-Z+1 \geq 0$. \\
1 & $\phi_{o}=2 \pi-2 \cos ^{-1} \frac{\left[\{(D-d) / 2-3(T / 4)\}^{2}+\left\{D / 2-(T / 4)-D_{b}\right\}^{2}-\{d / 2+(T / 4)\}^{2}\right]}{2\{(D-d) / 2-3(T / 4)\}\left\{D / 2-(T / 4)-D_{b}\right\}}$ \\
& With $T=D-d-2 D_{b}$. \\
5 & $g_{4}(X)=\varsigma B_{w}-D_{b} \geq 0$ \\
6 & $g_{5}(X)=D_{m}-(0.5-e)(D+d) \geq 0$ \\
7 & $g_{6}(X)=(0.5+e)(D+d)-D_{m} \geq 0$ \\
$g_{7}(X)=0.5\left(D-D_{m}-D_{b}\right)-\varepsilon D_{b} \geq 0$
\end{tabular}

Table 5: Design variable bounds

\begin{tabular}{lll}
\hline Design variable & Lower limit & Upper limit \\
\hline$D_{m}(\mathrm{~mm})$ & $0.5(D+d)$ & $0.6(D+d)$, \\
$D_{B}(\mathrm{~mm})$ & $0.15(D-d)$ & $0.45(D-d)$, \\
$Z$ & 4 & 50 \\
$f_{i}$ & 0.515 & 0.6 \\
$f_{o}$ & 0.515 & 0.6 \\
$K_{D \text { min }}$ & 0.40 & 0.50
\end{tabular}




\begin{tabular}{lll}
$K_{D \max }$ & 0.60 & 0.90 \\
$\varepsilon$ & 0.15 & 0.40 \\
$e$ & 0.02 & 0.10 \\
$\zeta$ & 0.60 & 0.85 \\
\hline
\end{tabular}

Table6: External dimensions of standard ball bearings.

\begin{tabular}{llllll}
\hline $\begin{array}{l}\text { Bearing } \\
\text { Number }\end{array}$ & $\begin{array}{l}\text { Standard } \\
\text { dimensions } \\
(\mathrm{mm})\end{array}$ & boundary & $\begin{array}{l}\text { Dynamic } \\
\text { Capacity, } \\
\mathrm{kN}\end{array}$ & $\begin{array}{l}\text { Limiting } \\
\text { speed, } \\
\mathrm{Rpm}\end{array}$ \\
\cline { 2 - 4 } & $D$ & $d$ & $B$ & & \\
6200 & 30 & 10 & 9 & 5.4 & 36000 \\
6202 & 35 & 15 & 11 & 8.06 & 28000 \\
6204 & 47 & 20 & 14 & 13.5 & 20000 \\
6206 & 62 & 30 & 16 & 20.3 & 15000 \\
6208 & 80 & 40 & 18 & 32.5 & 11000 \\
6210 & 90 & 50 & 20 & 37.1 & 10000 \\
6212 & 110 & 60 & 22 & 55.3 & 8000 \\
6214 & 125 & 70 & 24 & 63.7 & 7000 \\
6216 & 140 & 80 & 26 & 72.8 & 6000 \\
6218 & 160 & 90 & 30 & 73.5 & 5300 \\
\hline
\end{tabular}

Table 7: Material properties (steel)

\begin{tabular}{ll}
\hline Description & Values \\
\hline Safe contact stress & $4000 \mathrm{MPa}$ \\
Young's modulus & $210 \mathrm{GPa}$ \\
Poisson's ratio & 0.3 \\
Dynamic Viscosity & $162 \times 10^{-11} \mathrm{~N}-\mathrm{s} / \mathrm{mm}^{2}$ \\
\hline
\end{tabular}

Table 8: Variations in GA parameter and favored values.

\begin{tabular}{lll}
\hline G.A Parameter & Variation & Favored Value \\
\hline Crossover probability & $0.7-0.9$ & 0.7 \\
Mutation probability & $0-0.111$ & 0.1 \\
Crossover distribution index & $1-100$ & 10 \\
Mutation distribution index & $1-500$ & 10 \\
Random seed & $0-1$ & 0.2 \\
\hline
\end{tabular}

\section{Multi Objective Optimization and Evolutionary Algorithms}

Optimization can be described as a process that can make the existing solution better within the given variable constraints. Any engineering design problem has a multitude of objectives to optimize by using constrained parameters. For such problems, there exists a unique vector in the objective space for every parameter vector $\boldsymbol{x}$ in decision space. The mapping takes place between an $i$ dimensional solution vector and an $m$-dimensional objective vector and hence the name 'vector optimization method' (Fig. 5). Most of the time, due to the conflicting nature of objective functions, a unique optimum solution for a multi-objective problem does not exist and hence leads to Pareto fronts. The solutions in the Pareto optimal sets are non-dominated in the entire feasible parameter space. 
Thus, the main task in the MOOP is to get these multiple optimum solutions that will form Pareto fronts.

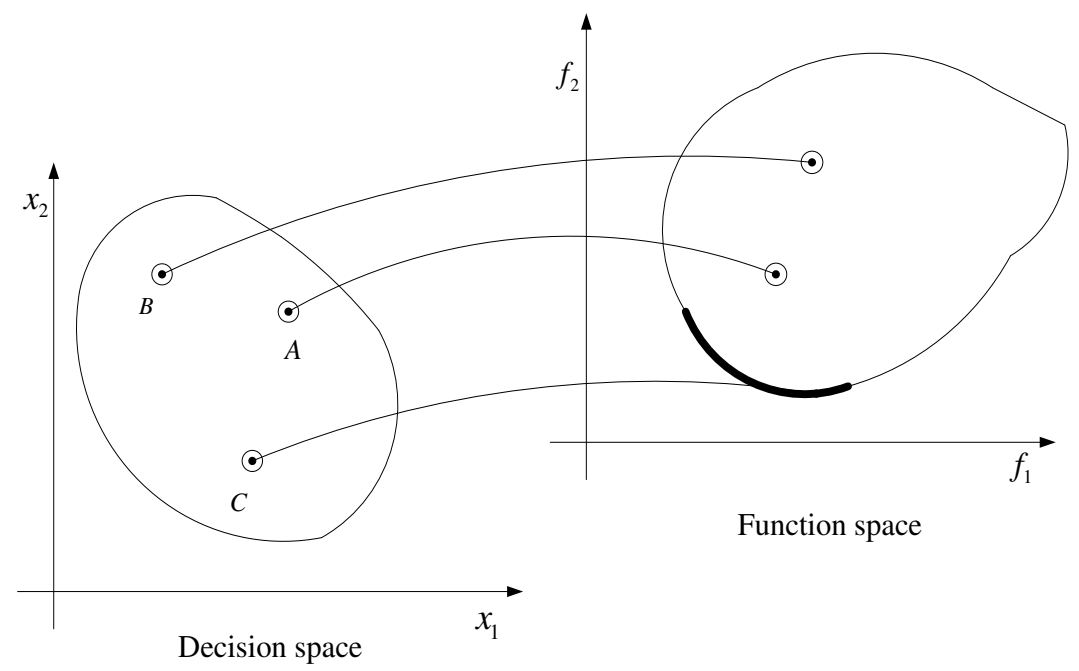

Fig. 5. Decision space and the corresponding function space with Pareto front

The concept of domination that is used in the MOOP is explained. A solution $\boldsymbol{x}$ is said to dominate (more optimal) another solution $Y$, when the solution $\mathbf{x}$ is no worse than $\mathbf{y}$ in all objectives and $\boldsymbol{x}$ is strictly better than $\mathbf{y}$ in at least one objective (Deb et al. 2002). Assuming all the objectives are of the maximization type, the dominance of $\mathbf{x}$ over $\mathbf{y}$ is given as,

$$
\mathbf{x f} \mathbf{y}: \Leftrightarrow\left\{f_{m}(\mathbf{x}) \check{Z} f_{m}(\mathbf{y}) \forall m \text { and } f_{m}(\mathbf{x})>f_{m}(\mathbf{y}) \text { for at least one } m\right\}
$$

$\mathbf{x} \mathrm{f} \mathbf{y}$ means $\boldsymbol{x}$ dominates over $\boldsymbol{y}$. In a local search space, the collection of such non-dominated solutions is termed as non-dominated front. Pareto-optimal front is nothing but the global nondominated front. Hence, we can say that, all POFs are non-dominated but the converse is not true. Depending on the linearity of the constraints, the MOOP could be linear or non-linear.

Evolutionary Algorithms (EA) are inspired from the principle of evolution in establishing the search and optimization methodology. The advantage of EAs is that they can search for and maintain multiple solutions in one single simulation run, similar to those maintained by a living population of any biological species. Since EAs deal with the population of solutions rather a single one, these methods are tailored for optimization. Various algorithms available for solving the MOOP are: NonElitist MOEAs and Elitist MOEAs \{Distance based Pareto GA (DPGA), Strength Pareto Evolutionary Algorithm (SPEA), Artificial Bee Colony algorithm (ABC), SPEA-II, Non-dominated Sorting Genetic Algorithm (NSGA-II) \}, etc. Due to factors such as the elite-preserving strategy, the explicit diversitypreserving mechanism and its overall ability to preserve a better solution spread (Deb et al., 2020), NSGA-II has been employed for solving the present problem. Being popular in research and application in various domains, vast research is done in the past two decades on multi-objective evolutionary algorithms.

The computer code for the algorithm, NSGA-II was developed by Kanpur Genetic Algorithm Laboratory (KanGAL), IIT Kanpur, in C language to which minor changes have been made to cater the needs of the present optimization problem. All the variables and their ranges, numerical constants, and boundary values have been coded in the appropriate format for getting the optimized results of the bearing. The design variables could be represented either as binary-coded or as real-coded parameters. The flow chart of NSGA-II applicable for the present case is depicted in Fig. 6. 


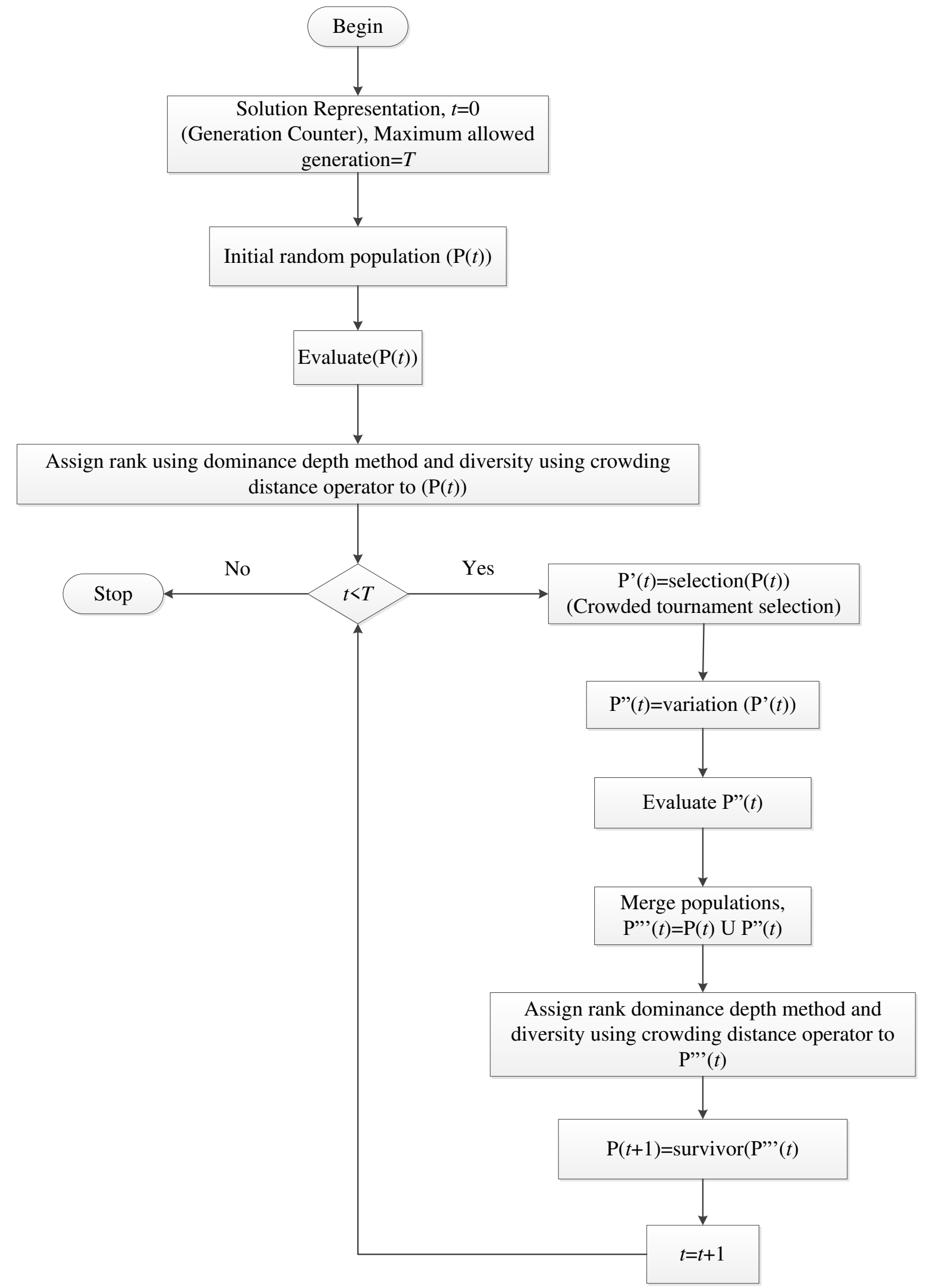

Fig. 6. Flowchart of NSGA-II algorithm

\section{Numerical simulation and discussions.}

In the present case of optimization of ball bearings, the selected design parameter vector is encoded as real-coded variables and the NSGA-II code is modified to take number of balls, $Z$, as an integer value. Material properties are given in Table 7, standard outer dimensions are given in Table 6, 
which have been taken from SKF bearing catalogue (2005) and variable bounds for ten design variables are given in Table 5. These are obtained from constraints 2 to 9. A subroutine has been written to give the range for design variables with bearing outer dimensions, material properties of bearing

and lubricant as the input.

Similar to the design variables, the GA parameters also have a need to be optimized as they give maximum spread in the variable space. The values of these GA parameters are varied in their respective ranges (Deb et al., 2002) and the parameter values with optimum objective function values have been selected. The minimum and maximum limit on GA parameters and their optimum values are given in Table 8.

In the present problem, three objective functions have been chosen for optimization and they are $C_{d}, h_{\min }$ and $T_{\max }$, which have been optimized individually and simultaneously. The optimization is performed on a set of standard catalogue bearings. The design parameter vectors obtained are given in Tables 9 through 15. The optimized dimensions for a set of ten standard bearings for the single objective optimization of $C_{d}, h_{\min }$ and $T_{\max }$ are given in Tables 9, 10 and 11, respectively. The optimized dimensions of the bearing taking simultaneous objective functions are given in Tables 12 through 15.

To compare the fatigue life of optimized bearings with those of standard bearings and with those of Tiwari and Chandran (2015), life comparison factor $(\lambda)$ has been used. Let $C_{d_{-} \text {new }}$ and $C_{d_{-} \text {std }}$ be the life comparison factors of optimized bearing and standard bearing, respectively and consequently we have,

$$
\lambda=\left(C_{d_{g}} / C_{d_{s}}\right)^{3}
$$

and the values are given in the respective tables. The life comparison factors calculated show that the optimized designs have high fatigue life than the standard bearings and the second comparison with results of ABC (2015) show that NSGA-II found better solutions within the given bounds.

The Pareto fronts for the bearing type 6200 are shown in Figures 10 through 13. For multi-objective optimization, a multitude of trade-off solutions are obtained and all these solutions are optimum giving the designer a choice to select bearing according to his preferences but a solution called knee solution is tabulated for each bearing because it is the solution on the Pareto front such that a small betterment in one objective leads to large downturn for other objectives. Schematic diagrams of the bearings optimized for the single and triple objective optimization are shown in Figures 11 through 14.

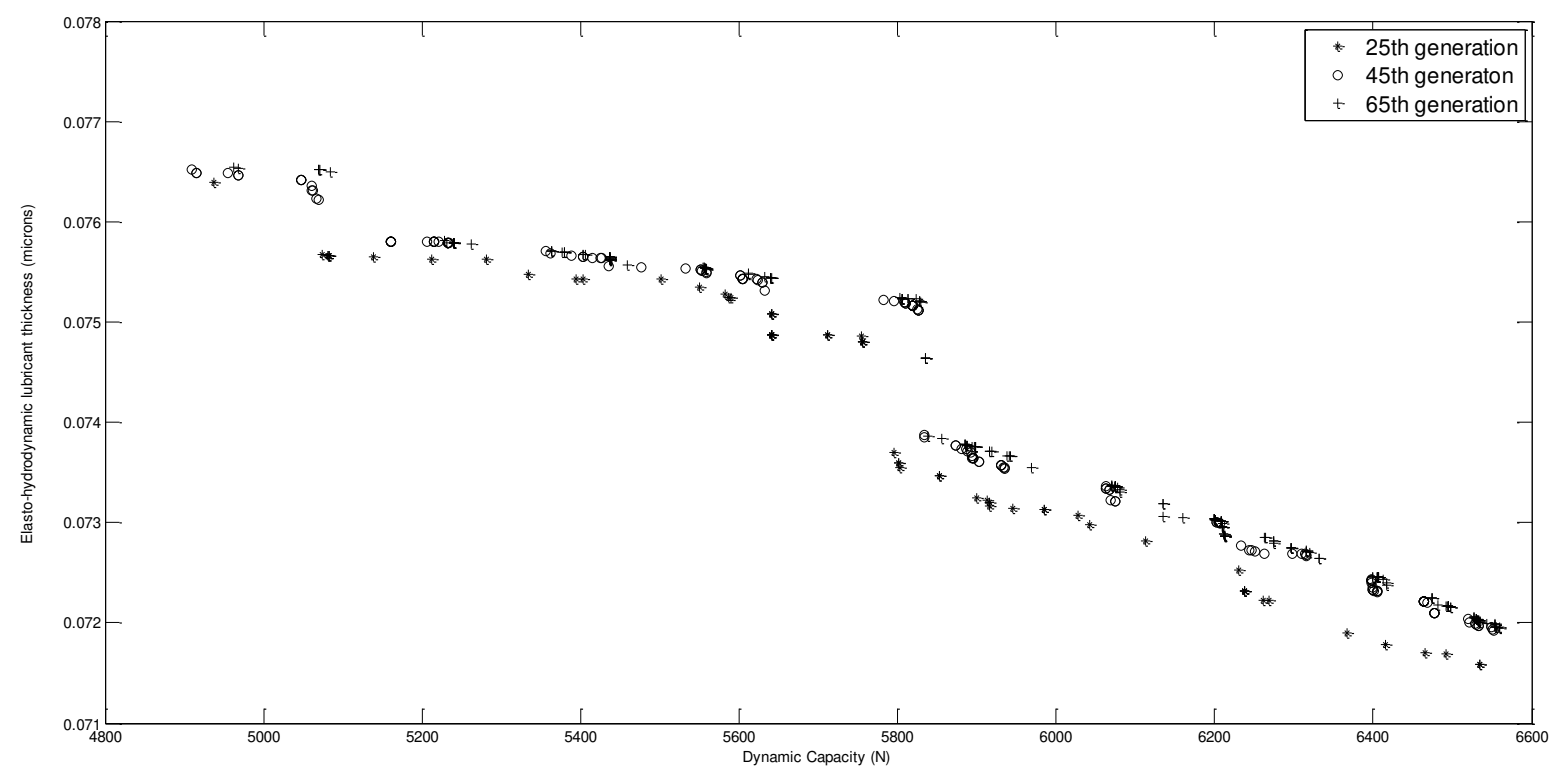

Fig. 7. Convergence of $C_{d}-h_{\min }$ Pareto front with generations for ball bearing configuration 6200. 


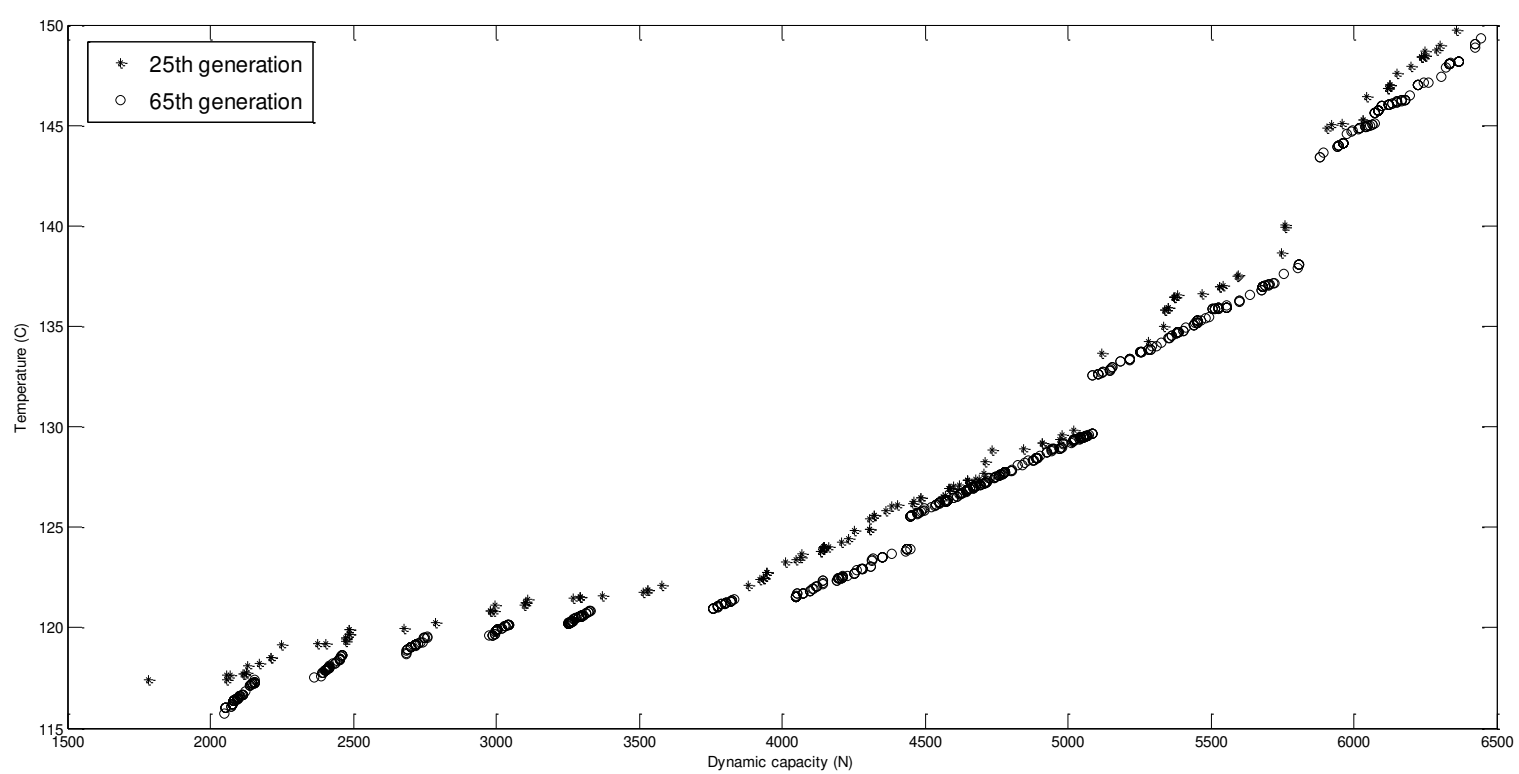

Fig. 8. Convergence of $C_{d}-T_{\max }$ Pareto front with generations for ball bearing configuration 6200.

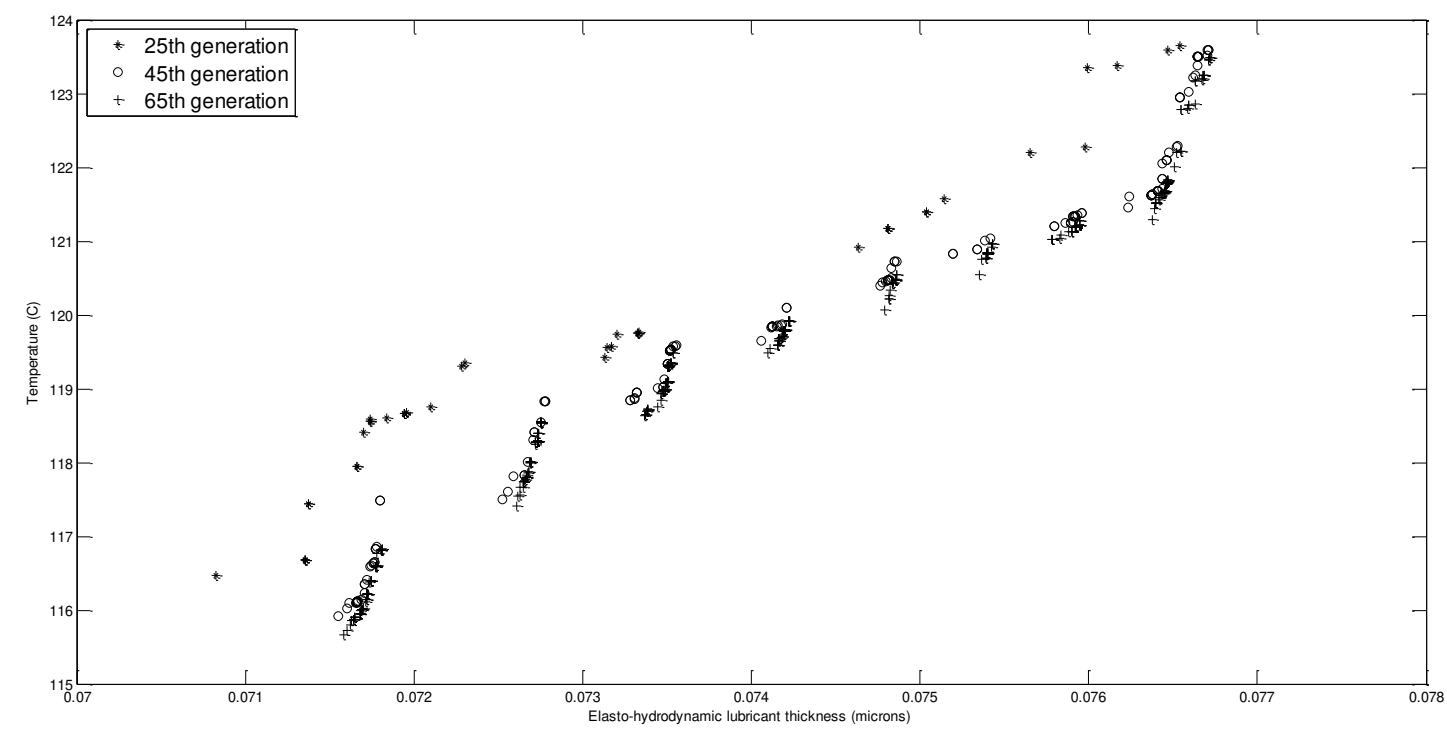

Fig. 9. Convergence of $h_{\min }-T_{\max }$ Pareto front with generations for ball bearing configuration 6200.

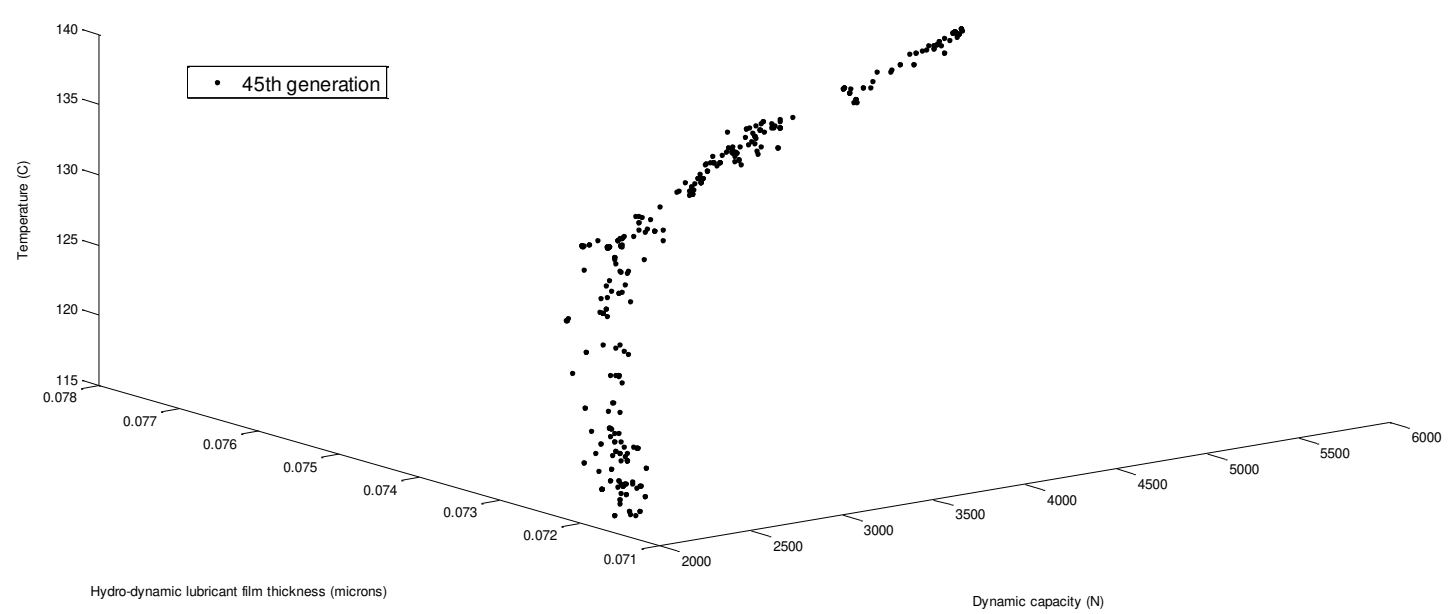

Fig. 10. Pareto optimal surface obtained by MOO of $C_{d^{-}} h_{\min }-T_{\max }$ ball bearing configuration 6200 . 
Table 9: Dynamic load carrying capacity optimization and improvement over catalogue values and values with $\mathrm{ABC}$.

\begin{tabular}{clllllllllllll}
\hline $\begin{array}{c}\text { Bearing } \\
\text { Number }\end{array}$ & $\begin{array}{c}D_{m} \\
(\mathrm{~mm})\end{array}$ & $\begin{array}{c}D_{B} \\
(\mathrm{~mm})\end{array}$ & $Z$ & $f_{i}$ & $f_{o}$ & $K_{D \min }$ & $K_{D \max }$ & $\xi$ & $l$ & $\zeta$ & $C_{d}$ & $\lambda_{\text {std }}$ & $\lambda_{A B C}$ \\
\hline 6200 & 20.06 & 6.21 & 8 & 0.515 & 0.515 & 0.4438 & 0.6977 & 0.3 & 0.0444 & 0.8041 & 6596.35 & 1.82 & 1.30 \\
6202 & 26.06 & 6.87 & 9 & 0.515 & 0.515 & 0.4948 & 0.8041 & 0.15 & 0.0479 & 0.899 & 8972.52 & 1.38 & 2.05 \\
6204 & 35.01 & 9.23 & 9 & 0.515 & 0.515 & 0.4912 & 0.8999 & 0.15 & 0.0995 & 0.7941 & 15244.3 & 1.44 & 1.99 \\
6206 & 46.08 & 12.24 & 9 & 0.515 & 0.515 & 0.4208 & 0.8647 & 0.15 & 0.0501 & 0.8948 & 25324.6 & 1.94 & 2.73 \\
6208 & 60.0 & 15.38 & 9 & 0.515 & 0.515 & 0.4999 & 0.8949 & 0.15 & 0.0784 & 0.8999 & 38474.1 & 1.66 & 2.84 \\
6210 & 70.0 & 15.38 & 10 & 0.515 & 0.515 & 0.4414 & 0.8906 & 0.15 & 0.0473 & 0.8999 & 42190.7 & 1.47 & 3.02 \\
6212 & 85.05 & 19.19 & 10 & 0.515 & 0.515 & 0.4636 & 0.8476 & 0.15 & 0.0307 & 0.8989 & 62646.5 & 1.45 & 2.95 \\
6214 & 97.00 & 21.54 & 10 & 0.515 & 0.515 & 0.4205 & 0.8940 & 0.15 & 0.0996 & 0.8999 & 77223.3 & 1.78 & 3.18 \\
6216 & 111.59 & 21.85 & 11 & 0.515 & 0.515 & 0.4999 & 0.8998 & 0.15 & 0.0467 & 0.8999 & 85070.3 & 1.59 & 2.30 \\
6218 & 125.63 & 21.40 & 12 & 0.515 & 0.515 & 0.4776 & 0.6903 & 0.30 & 0.0892 & 0.8997 & 86682.6 & 1.64 & 1.18 \\
\hline
\end{tabular}

Table 10: Elasto-hydrodynamic minimum film thickness optimization.

\begin{tabular}{clllllllllll}
$\begin{array}{c}\text { Bearing } \\
\text { Number }\end{array}$ & $\begin{array}{c}D_{m} \\
(\mathrm{~mm})\end{array}$ & $\begin{array}{c}D_{B} \\
(\mathrm{~mm})\end{array}$ & $Z$ & $f_{i}$ & $f_{o}$ & $K_{D \min }$ & $K_{D \max }$ & $\xi$ & $e$ & $\zeta$ & $\begin{array}{c}h_{\min } \\
\mu m\end{array}$ \\
\hline 6200 & 22.41 & 4.71 & 10 & 0.515 & 0.573 & 0.4657 & 0.8272 & 0.3 & 0.0985 & 0.6970 & 0.076549 \\
6202 & 27.28 & 5.94 & 10 & 0.515 & 0.5899 & 0.4883 & 0.6147 & 0.15 & 0.0483 & 0.7858 & 0.079099 \\
6204 & 36.38 & 11.23 & 9 & 0.585 & 0.593 & 0.4593 & 0.6002 & 0.26 & 0.0441 & 0.6649 & 0.106807 \\
6206 & 49.6 & 9.53 & 11 & 0.515 & 0.544 & 0.4993 & 0.8797 & 0.15 & 0.0795 & 0.8942 & 0.093200 \\
6208 & 63.95 & 12.34 & 11 & 0.515 & 0.594 & 0.4886 & 0.8167 & 0.15 & 0.0941 & 0.8721 & 0.097700 \\
6210 & 71.78 & 14.01 & 11 & 0.515 & 0.562 & 0.4780 & 0.8235 & 0.15 & 0.0393 & 0.8571 & 0.103871 \\
6212 & 87.77 & 17.10 & 11 & 0.515 & 0.5845 & 0.4996 & 0.8882 & 0.15 & 0.0605 & 0.8575 & 0.109086 \\
6214 & 99.69 & 19.47 & 11 & 0.515 & 0.599 & 0.4999 & 0.8156 & 0.15 & 0.0999 & 0.8999 & 0.114169 \\
6216 & 111.65 & 21.8 & 11 & 0.515 & 0.574 & 0.4083 & 0.8906 & 0.15 & 0.0224 & 0.8489 & 0.115927 \\
6218 & 125.73 & 21.41 & 12 & 0.515 & 0.575 & 0.4559 & 0.7836 & 0.3 & 0.0847 & 0.8572 & 0.117534 \\
\hline
\end{tabular}

Table 11: Maximum bearing temperature optimization.

\begin{tabular}{clllllllllll}
\hline $\begin{array}{c}\text { Bearing } \\
\text { Number }\end{array}$ & $\begin{array}{l}D_{m} \\
(\mathrm{~mm})\end{array}$ & $\begin{array}{c}D_{B} \\
(\mathrm{~mm})\end{array}$ & $Z$ & $f_{i}$ & $f_{o}$ & $K_{D \min }$ & $K_{D \max }$ & $\xi$ & $e$ & $\zeta$ & $\begin{array}{l}T_{\max } \\
{ }^{0} C\end{array}$ \\
\hline 6200 & 23.60 & 4.0 & 8 & 0.599 & 0.594 & 0.4 & 0.7835 & 0.3 & 0.0567 & 0.6500 & 115.4 \\
6202 & 29.8 & 4.0 & 9 & 0.599 & 0.552 & 0.4 & 0.8425 & 0.15 & 0.0916 & 0.7780 & 114 \\
6204 & 39.98 & 5.40 & 9 & 0.599 & 0.554 & 0.4 & 0.6784 & 0.15 & 0.0559 & 0.6122 & 131.2 \\
6206 & 53.68 & 6.4 & 10 & 0.599 & 0.555 & 0.4 & 0.6472 & 0.15 & 0.0677 & 0.7707 & 129.8 \\
6208 & 67.28 & 8.0 & 10 & 0.599 & 0.516 & 0.4 & 0.6389 & 0.15 & 0.0291 & 0.6078 & 146.2 \\
6210 & 72.31 & 8.0 & 11 & 0.599 & 0.52 & 0.4 & 0.6012 & 0.15 & 0.0365 & 0.6001 & 142.4 \\
6212 & 85.00 & 10.0 & 11 & 0.599 & 0.515 & 0.4 & 0.6008 & 0.1506 & 0.0200 & 0.6729 & 160.5 \\
6214 & 97 & 11.0 & 11 & 0.599 & 0.515 & 0.4 & 0.600 & 0.15 & 0.02 & 0.600 & 158.3 \\
6216 & 110 & 12 & 11 & 0.599 & 0.515 & 0.4 & 0.60 & 0.1587 & 0.0201 & 0.6041 & 155.8 \\
6218 & 138.92 & 16.4 & 12 & 0.5841 & 0.575 & 0.46 & 0.6592 & 0.3824 & 0.0697 & 0.8287 & 160.1 \\
\hline
\end{tabular}

Table 12: MOO of dynamic load carrying capacity and elasto-hydrodynamic minimum film thickness and their improvement over standard bearings.

\begin{tabular}{ccccccccccccccc}
$\begin{array}{c}\text { Bearing } \\
\text { Number }\end{array}$ & $\begin{array}{c}D_{m} \\
(\mathrm{~mm})\end{array}$ & $\begin{array}{c}D_{B} \\
(\mathrm{~mm})\end{array}$ & $Z$ & $f_{i}$ & $f_{o}$ & $K_{D \min }$ & $K_{D \max }$ & $\xi$ & $e$ & $\zeta$ & $\begin{array}{l}C_{d} \\
k N\end{array}$ & $\begin{array}{c}h_{\min } \\
\mu m\end{array}$ & $\lambda_{\text {std }}$ \\
\hline 6200 & 20.20 & 6.12 & 8 & 0.515 & 0.515 & 0.4046 & 0.6739 & 0.3 & 0.020 & 0.7982 & 6474.489 & 0.07223 & 1.72 \\
6202 & 26.07 & 6.87 & 9 & 0.515 & 0.515 & 0.4146 & 0.6939 & 0.15 & 0.5225 & 0.6603 & 8958.926 & 0.07801 & 1.37 \\
6204 & 35.02 & 9.21 & 9 & 0.515 & 0.515 & 0.4494 & 0.7869 & 0.15 & 0.0566 & 0.7209 & 15218.46 & 0.08378 & 1.43 \\
6206 & 46.27 & 12.10 & 9 & 0.515 & 0.515 & 0.4016 & 0.7608 & 0.15 & 0.0316 & 0.7848 & 24885.42 & 0.09191 & 1.84 \\
6208 & 61.96 & 13.88 & 10 & 0.515 & 0.515 & 0.4896 & 0.8287 & 0.15 & 0.0514 & 0.8999 & 34993.87 & 0.09763 & 1.25 \\
6210 & 70.00 & 15.38 & 10 & 0.515 & 0.515 & 0.461 & 0.8498 & 0.15 & 0.0712 & 0.8999 & 42189.51 & 0.10371 & 1.47
\end{tabular}


$\begin{array}{llllllllllllll}6212 & 87.76 & 17.11 & 11 & 0.515 & 0.515 & 0.4852 & 0.8999 & 0.15 & 0.0601 & 0.8981 & 54769.77 & 0.10909 & 0.97\end{array}$

$\begin{array}{llllllllllllll}6214 & 99.68 & 19.48 & 11 & 0.515 & 0.515 & 0.4486 & 0.7918 & 0.15 & 0.0793 & 0.8449 & 69158.44 & 0.11407 & 1.28\end{array}$

$\begin{array}{llllllllllllll}6216 & 111.5 & 21.85 & 11 & 0.515 & 0.515 & 0.4886 & 0.8648 & 0.15 & 0.0999 & 0.8999 & 84068.85 & 0.11094 & 1.54\end{array}$

$\begin{array}{llllllllllllll}6218 & 125.7 & 21.42 & 12 & 0.515 & 0.515 & 0.4999 & 0.6915 & 0.3 & 0.0751 & 0.8938 & 84817.87 & 0.10753 & 1.54\end{array}$

Table 13: MOO of dynamic capacity and maximum bearing temperature and comparison with catalogue values.

\begin{tabular}{cccccccccccccc}
\hline $\begin{array}{c}\text { Bearing } \\
\text { Number }\end{array}$ & $\begin{array}{c}D_{m} \\
(\mathrm{~mm})\end{array}$ & $\begin{array}{c}D_{B} \\
(\mathrm{~mm})\end{array}$ & $Z$ & $f_{i}$ & $f_{o}$ & $K_{D \min }$ & $K_{D \max }$ & $\xi$ & $e$ & $\zeta$ & $C_{d}$ & $\begin{array}{l}T_{\max } \\
k N\end{array}$ & $\lambda_{\text {std }}$ \\
\hline 6200 & 21.43 & 5.35 & 9 & 0.515 & 0.515 & 0.4003 & 0.6023 & 0.3001 & 0.0313 & 0.6750 & 5776.471 & 127.6 & 1.2 \\
6202 & 27.23 & 5.97 & 10 & 0.515 & 0.515 & 0.4020 & 0.6433 & 0.15 & 0.0371 & 0.6037 & 7668.182 & 128.2 & 0.86 \\
6204 & 36.62 & 7.98 & 10 & 0.515 & 0.515 & 0.4049 & 0.6556 & 0.15 & 0.0344 & 0.6001 & 12958.01 & 140.2 & 0.88 \\
6206 & 49.84 & 9.34 & 11 & 0.515 & 0.515 & 0.4001 & 0.6184 & 0.1503 & 0.0211 & 0.6358 & 19419.18 & 143.5 & 0.88 \\
6208 & 64.58 & 11.84 & 11 & 0.515 & 0.515 & 0.4201 & 0.7209 & 0.1502 & 0.0368 & 0.7603 & 33249.05 & 154.8 & 1.07 \\
6210 & 74.13 & 12.14 & 12 & 0.515 & 0.515 & 0.4004 & 0.7617 & 0.1520 & 0.0214 & 0.6481 & 38164.29 & 150.0 & 1.09 \\
6212 & 90.24 & 15.05 & 12 & 0.515 & 0.515 & 0.4338 & 0.7574 & 0.1504 & 0.0230 & 0.7909 & 52915.09 & 168.7 & 0.88 \\
6214 & 101.69 & 17.19 & 12 & 0.515 & 0.515 & 0.4149 & 0.6891 & 0.1643 & 0.0365 & 0.8791 & 68630.97 & 166.9 & 1.25 \\
6216 & 113.72 & 19.56 & 12 & 0.515 & 0.515 & 0.4087 & 0.8258 & 0.1606 & 0.0434 & 0.7809 & 73691.34 & 165.9 & 1.04 \\
6218 & 133.57 & 17.04 & 14 & 0.515 & 0.515 & 0.4712 & 0.6789 & 0.3246 & 0.0290 & 0.6106 & 80855.02 & 166.7 & 1.33 \\
\hline
\end{tabular}

Table 14: MOO of elasto-hydrodynamic minimum film thickness and maximum bearing temperature.

\begin{tabular}{cllllllllllll}
$\begin{array}{c}\text { Bearing } \\
\text { Number }\end{array}$ & $\begin{array}{c}D_{m} \\
(\mathrm{~mm})\end{array}$ & $\begin{array}{c}D_{B} \\
(\mathrm{~mm})\end{array}$ & $Z$ & $f_{i}$ & $f_{o}$ & $K_{D \min }$ & $K_{D \max }$ & $\xi$ & $e$ & $\zeta$ & $\begin{array}{l}h_{\min } \\
\mu m\end{array}$ & $\begin{array}{l}T_{\max } \\
{ }^{0} C\end{array}$ \\
\hline 6200 & 23.59 & 4.0 & 8 & 0.515 & 0.515 & 0.5186 & 0.6339 & 0.3 & 0.0349 & 0.6 & 0.07476 & 120 \\
6202 & 29.78 & 4 & 10 & 0.515 & 0.587 & 0.4 & 0.7553 & 0.1507 & 0.0501 & 0.6093 & 0.07476 & 120.3 \\
6204 & 39.94 & 5.42 & 11 & 0.515 & 0.544 & 0.4011 & 0.6378 & 0.1501 & 0.0456 & 0.6041 & 0.08099 & 130.4 \\
6206 & 53.23 & 6.74 & 12 & 0.5152 & 0.5332 & 0.4027 & 0.7043 & 0.1505 & 0.0604 & 0.7574 & 0.08802 & 135.4 \\
6208 & 68.45 & 8.88 & 12 & 0.515 & 0.5398 & 0.4012 & 0.7367 & 0.15 & 0.0347 & 0.8149 & 0.09274 & 156.1 \\
6210 & 77.13 & 9.88 & 11 & 0.5151 & 0.5461 & 0.4043 & 0.6426 & 0.15 & 0.0311 & 0.6391 & 0.09767 & 153.9 \\
6212 & 93.46 & 12.71 & 10 & 0.515 & 0.5261 & 0.4021 & 0.7928 & 0.15 & 0.0494 & 0.6644 & 0.10319 & 172.9 \\
6214 & 106.27 & 14.40 & 10 & 0.515 & 0.5451 & 0.4140 & 0.6624 & 0.1503 & 0.0767 & 0.7573 & 0.10789 & 171.2 \\
6216 & 115.69 & 15.16 & 10 & 0.515 & 0.585 & 0.4111 & 0.6054 & 0.3012 & 0.0733 & 0.6784 & 0.10475 & 167.3 \\
6218 & 126.22 & 18.69 & 13 & 0.515 & 0.515 & 0.4454 & 0.6519 & 0.3389 & 0.0788 & 0.7279 & 010149 & 168.2 \\
\hline
\end{tabular}

Table 15: MOO of dynamic capacity, minimum film thickness and maximum temperature and comparison with catalogue values.

\begin{tabular}{ccccccccccccccc}
$\begin{array}{c}\text { Bearing } \\
\text { Number }\end{array}$ & $\begin{array}{c}D_{m} \\
(\mathrm{~mm})\end{array}$ & $\begin{array}{c}D_{B} \\
(\mathrm{~mm})\end{array}$ & $Z$ & $f_{i}$ & $f_{o}$ & $K_{D \min }$ & $K_{D \max }$ & $\xi$ & $e$ & $\zeta$ & $\begin{array}{l}C_{d} \\
k N\end{array}$ & $\begin{array}{l}h_{\min } \\
\mu m\end{array}$ & $\begin{array}{l}T_{\max } \\
{ }^{0} C\end{array}$ & $\lambda_{\text {std }}$ \\
\hline 6200 & 21.4 & 5.33 & 9 & 0.5151 & 0.5156 & 0.4108 & 0.7791 & 0.3 & 0.0833 & 0.6626 & 5736.4 & 0.0752 & 137.4 & 1.19 \\
6202 & 27.2 & 5.93 & 10 & 0.515 & 0.515 & 0.4009 & 0.6954 & 0.1519 & 0.0417 & 0.6608 & 7592.9 & 0.0789 & 130 & 0.83 \\
6204 & 36.5 & 8.02 & 10 & 0.515 & 0.515 & 0.4040 & 0.6778 & 0.1508 & 0.0367 & 0.6234 & 13051. & 0.0848 & 142 & 0.90 \\
6206 & 50.1 & 9.13 & 11 & 0.515 & 0.515 & 0.4056 & 0.6046 & 0.15 & 0.0209 & 0.6685 & 18666. & 0.0927 & 144 & 0.77 \\
6208 & 64.7 & 11.5 & 11 & 0.515 & 0.5153 & 0.4024 & 0.7614 & 0.1531 & 0.0259 & 0.6934 & 30044. & 0.0967 & 151 & 0.79 \\
6210 & 74.0 & 11.9 & 12 & 0.5151 & 0.515 & 0.4030 & 0.6855 & 0.1593 & 0.0313 & 0.7357 & 35178. & 0.1017 & 155.6 & 0.85 \\
6212 & 89.8 & 14.7 & 12 & 0.515 & 0.515 & 0.4182 & 0.6174 & 0.1574 & 0.0260 & 0.7185 & 50309. & 0.1067 & 170.3 & 0.75 \\
6214 & 103. & 13.2 & 12 & 0.515 & 0.5152 & 0.4276 & 0.7334 & 0.1658 & 0.0349 & 0.7315 & 65440. & 0.1035 & 170.4 & 1.08 \\
6216 & 115. & 18.3 & 12 & 0.515 & 0.515 & 0.4066 & 0.7112 & 0.1510 & 0.0546 & 0.8299 & 73048. & 0.1132 & 168.2 & 1.01 \\
6218 & 128. & 19.8 & 12 & 0.515 & 0.515 & 0.4818 & 0.6466 & 0.3030 & 0.0539 & 0.8620 & 76585. & 0.1136 & 170.2 & 1.13 \\
\hline
\end{tabular}




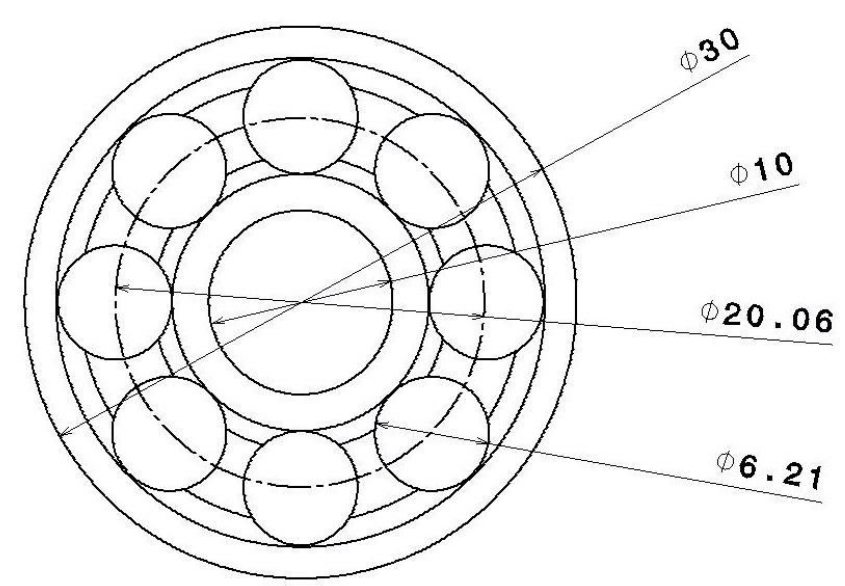

Fig. 11. Radial dimensions of optimized bearing for SOO of 6200 with $C_{d}$ as objective function.

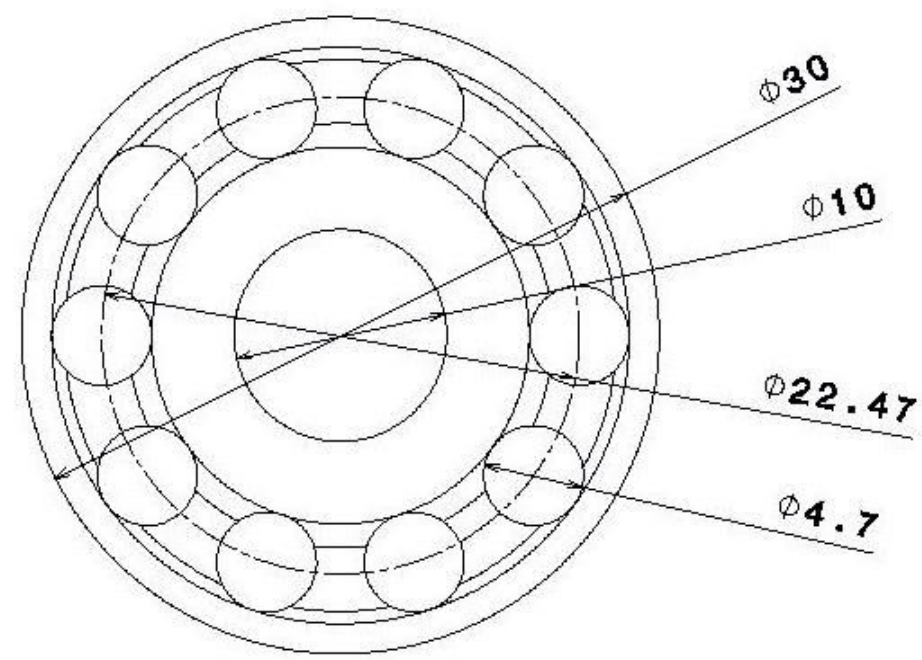

Fig. 12. Radial dimensions of optimized bearing for SOO of 6200 with $h_{\min }$ as objective function.

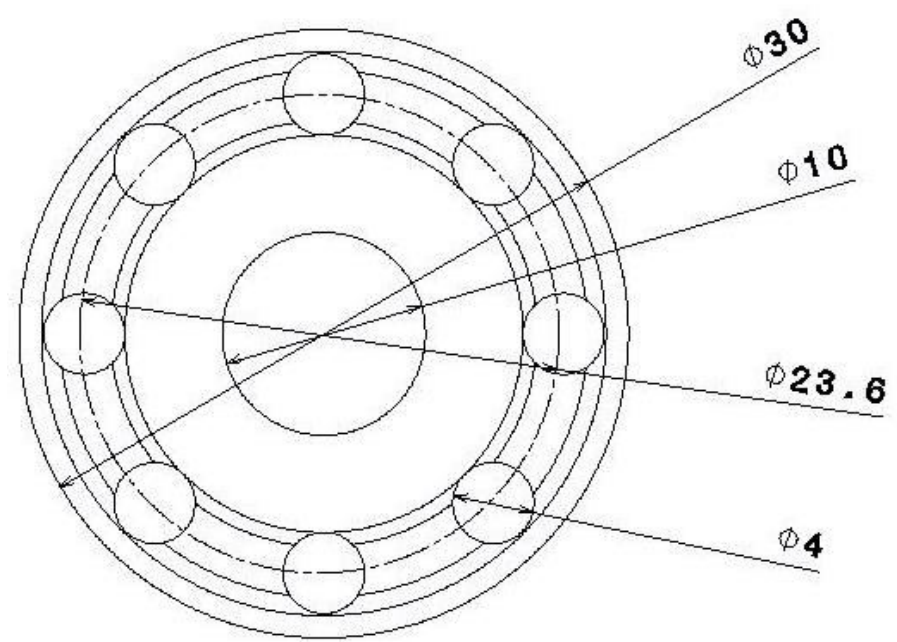

Fig. 13. Radial dimensions of optimized bearing for SOO of 6200 with $T_{\max }$ as objective function. 


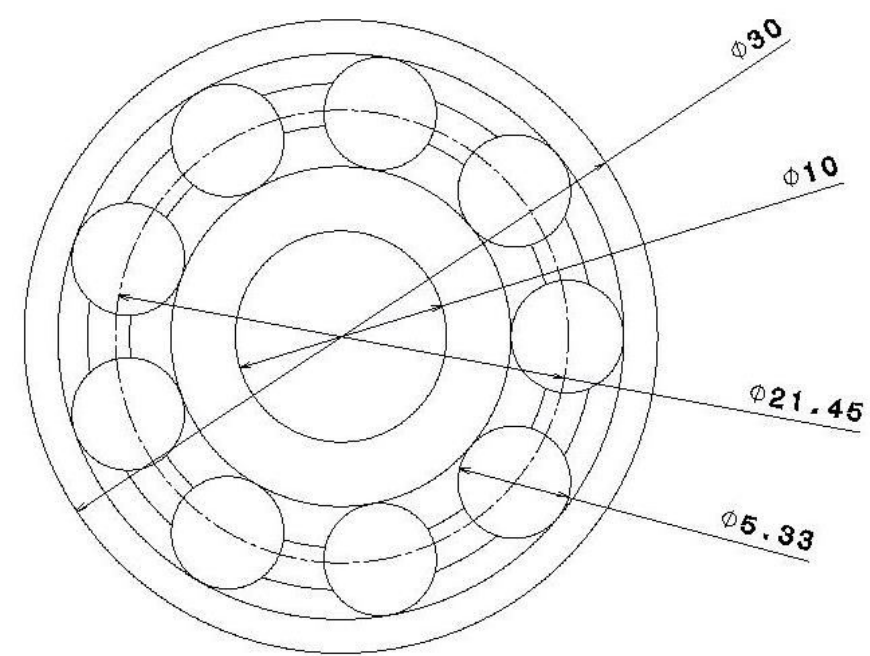

Fig. 14. Radial dimensions of optimized bearing for TOO of 6200.

\subsection{Discussions}

From the result tables (Table 9 to Table 15) of the optimized bearings, we can observe that the life comparison factors are more than 1 (Tables 9, 12, 13 and 15), which indicate that the bearings designed with the optimized dimensions have improved load carrying capacity when compared with standard catalogue bearings and those of the ABC algorithm (Table 9). The second comparison proves that the NSGA-II is successful in finding a better solution thus making it an efficient genetic algorithm

than the $\mathrm{ABC}$. The maximum temperatures reached are in the range of $114-160^{\circ} \mathrm{C}$ which is due to the fact that the selected bearings are operated at very high rotational velocities and to reduce these external cooling methods can be employed or a lubricant with high specific heat capacity can be chosen. Also, the proposed design methodology has the ability to predict temperatures at various locations at variable lubricant flow rates. Hence, it is possible to calculate the amount of lubricant required for having the required temperature beforehand. Also, during the course of this work, it has been found that there is a significant decrease in temperatures with increased lubricant flow rate. The lubricant thickness can be improved by using a lubricant of higher dynamic viscosity but a compromise has to be made since temperature tends to rise due to increase in viscous forces. On observing the results for the single and simultaneous optimizations, we can observe that the objective function values for the simultaneous optimization are lesser than the single optimization thus confirming the fact that the selected objectives are conflicting in nature. The optimal values for temperature in multi-objective problem are greater than those of the single objective function. This is due to the fact that the nature of optimization is 'minimization' for temperature. So, lower temperature corresponds to a more optimal solution than the higher temperature and hence we can observe higher temperatures in multi-objective optimization.

To confirm the feasibility of production of the bearings with obtained dimensions, schematic diagrams in cross-sectional view are drawn. From the figures of $C_{d}$ optimization (Fig. 11) we can observe that the design incorporates maximum rolling elements (balls) and diameter of each rolling element is also larger compared to other designs since $C_{d}$ is proportional to both those parameters. In the case of optimization of $h_{\min }$ (Fig. 12), we can see that there are a greater number of rolling elements. We can infer that this is to distribute the load to a greater number of balls so that the lubricant thickness is maximum. For the optimum design with $T_{\min }$ (Fig. 13), the number of rolling elements is minimum. With a smaller number of rolling elements, the heat generation at contact points due to friction and at rolling element surfaces due to lubricant slashing and churning will be less. That will lead to lesser temperature rise. With a greater number of rolling elements, the effect will be opposite. The point of contact of rolling elements is the point where heat is generated and it gets dissipated through the surrounding medium, which is mainly the lubricant. With a greater number of rolling element surface area in contact with lubricant will increase that will have more convection. Conduction will also increase but due to relatively smaller area of contact, it is relatively less. And finally, the design for 
simultaneous optimization (Fig. 14) is a combination of the above discussed factors, which has the number of balls and diameter of balls in between the extremes.

\section{Sensitivity Analysis}

Due to multiple reasons during manufacturing (man, machine and material), there occurs a deviation from the desired dimensions and this may or may not (if the design is robust) lead to change in performance of the part manufactured. The designed dimensions are said to be robust, if the machine element functions without much change in its performance even under such perturbations. Sensitivity analysis helps in assessing the sources and deviations from optimum values due to such perturbations and hence is an invaluable tool for building robust models. It allows the designer to assess the effect of variation in each parameter over the performance of bearing. Of the variables in design parameter vector, $D_{m}, D_{B}, f_{i}$ and $f_{o}$ are the parameters prone to manufacturing tolerances and hence chosen for sensitive analysis. The number of rolling elements (balls), $Z$, has not been included in the sensitivity analysis as it was assumed that no error would arise while placing the required number of balls inside the bearing. The chosen dimensions have been perturbed with a tolerance of $0.5 \%$ around the dimensions at the knee point and evaluate the robustness of design taking various combinations of manufacturing disturbances.

For illustration, the sensitivity analysis of bearing 6200 is illustrated. Here, the abovementioned design variables are perturbed and the objective function values are calculated for individual parameter perturbation (with all other design variables as constant) as well as for all possible combinations in a tolerance band of $\pm 0.5 \%$ around knee point solution. 500 design parameter sets have been taken and the objective function values are calculated. The maximum variation in $C_{d}$, $h_{\min }$ and $T_{\max }$ with change in variables is given in Table 16. From the table, we can observe that the design of bearings is robust for all the objective functions for small perturbations in the chosen variables except for $C_{d}$ which is sensitive for minor changes in $f_{i}$. Hence, it is recommended to maintain close tolerance on $f_{i}$ for the optimum load carrying capacity.

Table 16: Sensitivity of objective function values to change in design parameters.

\begin{tabular}{ccccccc}
\hline \multicolumn{2}{c}{ Dimensions perturbed } & \multicolumn{4}{c}{ Percentage change in objective function values } \\
\hline$D_{m}$ & $D_{B}$ & $f_{i}$ & $f_{o}$ & $C_{d}$ & $h_{\min }$ & $T_{\max }$ \\
\hline$\checkmark$ & & & & 0.0872 & 0.4606 & 0.3122 \\
& $\checkmark$ & & & 0.8113 & 0.1111 & 0.1443 \\
& & $\checkmark$ & & 5.7800 & 0.0361 & 0.0008 \\
& & & $\checkmark$ & 0.4052 & 0.0201 & 0.0006 \\
$\checkmark$ & $\checkmark$ & & & 0.8702 & 0.5570 & 0.4368 \\
$\checkmark$ & & $\checkmark$ & & 5.8093 & 0.4860 & 0.3122 \\
$\checkmark$ & & & $\checkmark$ & 0.4779 & 0.4606 & 0.3122 \\
& $\checkmark$ & $\checkmark$ & & 6.4477 & 0.1433 & 0.1443 \\
& $\checkmark$ & & $\checkmark$ & 1.1732 & 0.1111 & 0.1443 \\
& & $\checkmark$ & $\checkmark$ & 6.0638 & 0.0361 & 0.0008 \\
$\checkmark$ & $\checkmark$ & $\checkmark$ & & 6.4273 & 0.5476 & 0.4368 \\
$\checkmark$ & $\checkmark$ & & $\checkmark$ & 1.2106 & 0.5302 & 0.4368 \\
$\checkmark$ & & $\checkmark$ & $\checkmark$ & 5.9229 & 0.4860 & 0.3122 \\
& $\checkmark$ & $\checkmark$ & $\checkmark$ & 6.4929 & 0.1433 & 0.1443 \\
$\checkmark$ & $\checkmark$ & $\checkmark$ & $\checkmark$ & 6.2001 & 0.4900 & 0.4368 \\
\hline
\end{tabular}

\section{Conclusions}

To sum up, multi objective optimization has been performed on a set of standard catalogue ball bearings and the results are tabulated. Three objective functions (dynamic capacity, bearing temperature and elasto-hydrodynamic film thickness) have been optimized individually (SOO) and simultaneously (MOO) subject to non-linear constraints using NSGA-II. Inclusion of thermal effects in multi-objective optimization is novel, brings the model close to reality and hence the results could be correlated with experimentation. While performing MOO, the objectives are found to be conflicting 
and form a Pareto optimal front and the designer can decide which solution to take but the solution shown in the tables is the knee solution. Nonetheless, every solution on the POF is an optimal solution and one can choose any of the solution based on their preferences. The POFs are discontinuous owing to the fact that number of balls is taken as an integer. Life comparison factors are calculated with standard bearings as well as with optimized values using the $\mathrm{ABC}$ algorithm is a direct result of the optimization performed on the bearing and these are found to be $>1$ which indicates need for improvement. This also strengthens the argument that the existing design needs to and can be improved by optimization. Also, the method discusses here is advantageous in the fact that nonstandard bearings can be designed. Robustness of the optimized design is validated with the sensitivity analysis. As a further step, bearings could be manufactured with the calculated dimensions to check the improvement in performance.

\section{NOMENCLATURE}

A Area normal to the heat flow $\left(\mathrm{m}^{2}\right)$

$b_{m} \quad$ A factor in $C_{d}$ to accommodate modern technological development

$B \quad$ Width of bearing $(\mathrm{mm})$

$B^{\prime} \quad$ Coefficient of lubricant thermal expansion. $(1 / \mathrm{k})$

$C_{p} \quad$ Specific heat of lubricant $(\mathrm{J} / \mathrm{kg}-\mathrm{K})$

$C_{d} \quad$ Dynamic load capacity of the bearing $(\mathrm{kN})$

$C_{d_{g}} \quad$ Dynamic load capacity of optimized bearings by the GA $(\mathrm{kN})$

$C_{d_{s}} \quad$ Dynamic load capacity of bearings from standard catalogues $(\mathrm{kN})$

$C_{V}(X) \quad$ Constraint violation function

$D \quad$ Bore diameter of the bearing $(\mathrm{mm})$

$d_{i} \quad$ Inner raceway mean diameter $(\mathrm{m})$

$d_{o} \quad$ Outer raceway mean diameter $(\mathrm{m})$

$D \quad$ Outer diameter of the bearing $(\mathrm{mm})$

$D_{m} \quad$ Bearing pitch diameter (mm)

$D_{B} \quad$ Ball diameter $(\mathrm{mm})$

$D_{i} \quad$ Outer diameter of the inner ring $(\mathrm{mm})$

$D_{o} \quad$ Inner diameter of the outer ring $(\mathrm{mm})$

$D_{b} \quad$ Ball diameter (mm)

$D_{h} \quad$ Outer diameter of the housing (m)

E Parameter for mobility condition

$E \quad$ Modulus of elasticity (GPa)

$E^{\prime} \quad$ Ratio, $E^{\prime} /\left(1-v^{2}\right)$

$E_{i} \quad$ Modulus of elasticity of the inner-ring (GPa)

$E_{o} \quad$ Modulus of elasticity of the outer-ring (GPa)

$f_{o} \quad$ Factor depending up on the type of bearing

$f(X) \quad$ Objective vector

$g_{j}(X) \quad$ Constraint vector

$G \quad$ Acceleration due to gravity

Gr Grashof number

$H_{c} \quad$ Heat transferred through conduction $(\mathrm{Nm} / \mathrm{s})$

$H_{v} \quad$ Heat transferred through convection $(\mathrm{Nm} / \mathrm{s})$

$H_{r} \quad$ Heat transferred through radiation $(\mathrm{Nm} / \mathrm{s})$

$H_{f} \quad$ Heat generated $(\mathrm{Nm} / \mathrm{s})$

$H_{w} \quad$ Width of the housing (m)

$h_{\text {min }} \quad$ Minimum film thickness (m)

$h_{v} \quad$ Convective heat transfer coefficient $\left(\mathrm{W} / \mathrm{m}^{2} \mathrm{k}\right)$

$h_{k}(X) \quad$ Constraint vector

$i \quad$ Number of rows of rolling elements

$k \quad$ Thermal conductivity of the bearing (W/mK)

$k_{o} \quad$ Thermal conductivity of the lubricant (W/mK) 


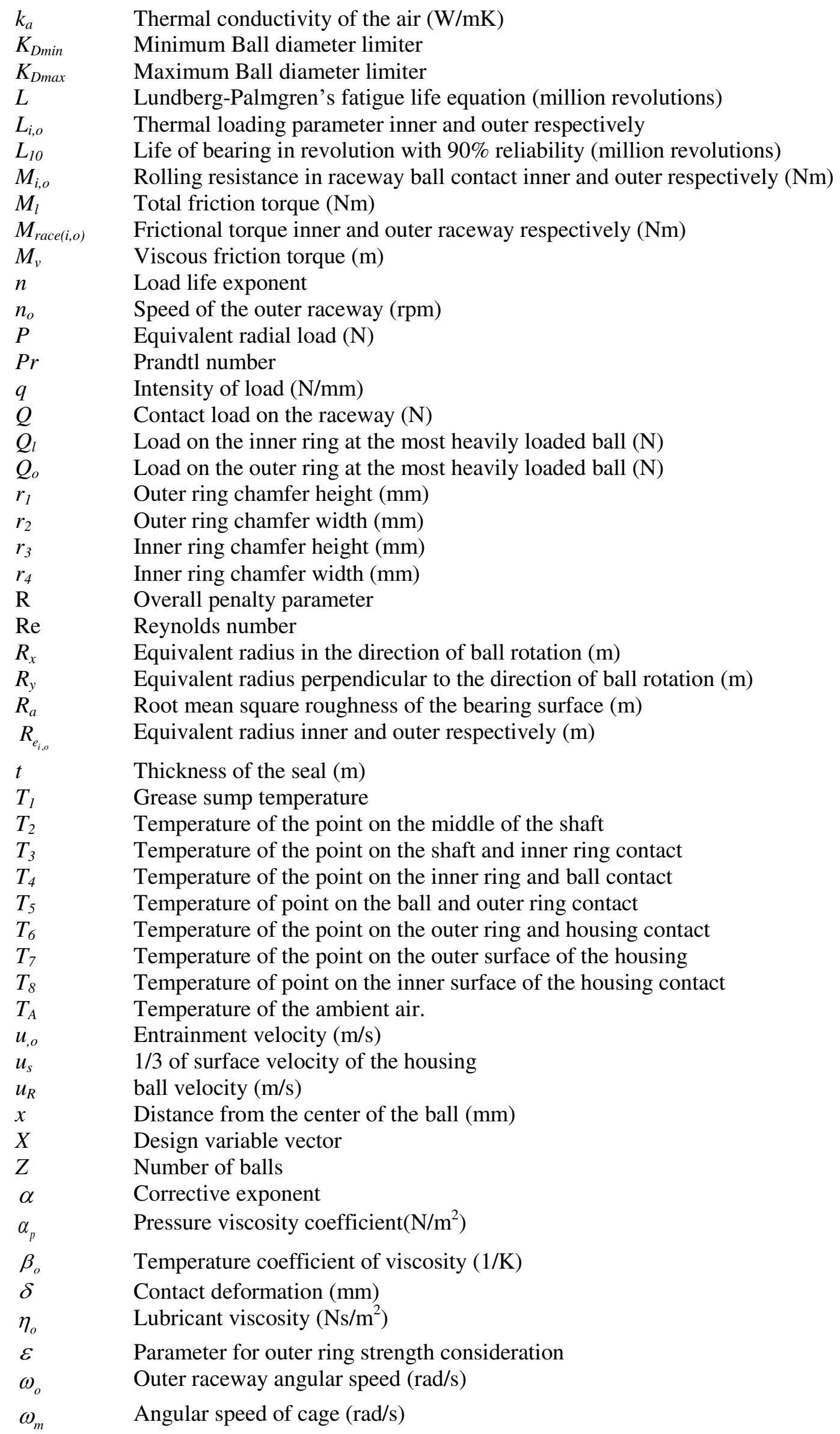




$\begin{array}{ll}\omega_{r} & \text { Angular speed of ball (rad/s) } \\ \gamma & \text { Ratio, } D_{B} \cos \alpha / D_{m} \\ \lambda & \text { Reduction factor for the manufacturing and mounting deviations } \\ \lambda_{l} & \text { Life factor } \\ v_{o} & \text { Kinematic viscosity of the lubricant }\left(\mathrm{m}^{2} / \mathrm{s}\right) \\ \theta & \text { Angle per rolling element }(360 / \mathrm{Z}) \\ S & \text { Parameter for the maximum radius of the ball } \\ \sum \rho & \text { Curvature sum of contacting bodies }(1 / \mathrm{mm}) \\ F(\rho) & \text { Curvature function of contacting bodies } \\ \sigma_{c} & \text { Contact stress (MPa) } \\ \sigma_{\max }^{l} & \text { Maximum contact stress for line contact }(\mathrm{MPa}) \\ \sigma_{\text {safe }} & \text { Safe contact stress (MPa) } \\ v & \text { Poisson's ratio } \\ v_{o} & \text { Kinematic viscosity of the lubricant }\left(\mathrm{cm}^{2} / \mathrm{s}\right) \\ \text { Subscripts } & \\ B & \text { Ball } \\ i & \text { Represents the inner raceway } \\ j & \text { Represents the constraint number } \\ n & \text { Number of components or elemental volumes } \\ o & \text { Represents the outer raceway }\end{array}$

\section{Declaration}

Availability of data and materials

All data and materials are in the manuscript itself.

\section{Competing interests}

There are no competing interests.

\section{Funding}

This research has not received any research funding.

\section{Authors' contributions}

The first author contribution is $65 \%$ (execution of whole formulation and coding and making draft version of the paper) and the second author contribution is 35\% (In generation of idea, supervision of work, and fine tuning the paper).

\section{Acknowledgements}

Not applicable. 


\section{References:}

[1] W. Changsen, Analysis of rolling element bearings. Mechanical Engineering Publications London, 1991.

[2] T. A. Harris and M. N. Kotzalas, Advanced concepts of bearing technology: rolling bearing analysis. Florida: CRC press, 2006.

[3] T. A. Harris and R. M. Barnsby, "Tribological performance prediction of aircraft gas turbine mainshaft ball bearings," Tribology transactions, vol. 41, no. 1, pp. 60-68, 1998.

[4] A. Seireg, "A survey of optimization of mechanical design," Journal of Engineering for Industry, vol. 94, no. 2, pp. 495-499, 1972.

[5] S. Andréason, "Load distribution in a taper roller bearing arrangement considering misalignment," ASME Journal of Tribology, vol. 6, no. 3, pp. 84-92, 1973.

[6] R. J. Parker and H. R. Signer, "Lubrication of High-Speed, Large Bore Tapered-Roller Bearings," Journal of Lubrication Technology, vol. 100, no. 1, pp. 31-38, 1978, doi: 10.1115/1.3453110.

[7] W. Jamison, J. Kauzlarich, and E. Mochel, "Geometric effects on the rib-roller contact in tapered roller bearings," AsLE Transactions, vol. 20, no. 1, pp. 79-88, 1977.

[8] C. L. Peng, X. P. Xie, and S. L. Chen, "Friction and Wear Analysis of Grease-Lubricated Ball Bearing Based on EHL Numerical Calculation," in Applied Mechanics and Materials, 2012, vol. 157: Trans Tech Publ, pp. 919-924.

[9] F. Kreith, R. M. Manglik, and M. S. Bohn, Principles of heat transfer. Cengage learning, 2012.

[10] A. A. Kendoush, "An approximate solution of the convective heat transfer from an isothermal rotating cylinder," International Journal of Heat and Fluid Flow, vol. 17, no. 4, pp. 439-441, 1996.

[11] E. Zitzler, "Evolutionary Algorithms for Multiobjective Optimization: Methods and Applications," Doctor of Technical Sciences, Swiss Federal Institute of Technology, Zurich, 13398, 1999.

[12] K. Deb, Optimization for engineering design: Algorithms and examples. PHI Learning Pvt. Ltd., 2012.

[13] K. Deb, "Multi-objective optimization using evolutionary algorithms. Vol. 16, 2001," ed: John Wiley \& Sons, United States, 2001.

[14] K. Deb, A. Pratap, S. Agarwal, and T. Meyarivan, "A fast and elitist multiobjective genetic algorithm: NSGA-II," IEEE transactions on evolutionary computation, vol. 6, no. 2, pp. 182197, 2002.

[15] I. Chakraborty, V. Kumar, S. B. Nair, and R. Tiwari, "Rolling element bearing design through genetic algorithms," Engineering Optimization, vol. 35, no. 6, pp. 649-659, 2003, doi: 10.1080/03052150310001624403.

[16] B. R. Rao and R. Tiwari, "Optimum design of rolling element bearings using genetic algorithms," Mechanism and machine theory, vol. 42, no. 2, pp. 233-250, 2007.

[17] K. S. Kumar, R. Tiwari, and R. Reddy, "Development of an optimum design methodology of cylindrical roller bearings using genetic algorithms," International journal for computational methods in engineering science and mechanics, vol. 9, no. 6, pp. 321-341, 2008.

[18] R. Tiwari, K. K. Sunil, and R. Reddy, "An optimal design methodology of tapered roller bearings using genetic algorithms," International Journal for Computational Methods in Engineering Science and Mechanics, vol. 13, no. 2, pp. 108-127, 2012.

[19] R. Tiwari and R. M. Chandran, "Multitude of objectives based optimum designs of cylindrical roller bearings with evolutionary methods," Journal of Tribology, vol. 137, no. 4, p. 041504, 2015.

[20] M. Kalyan and R. Tiwari, "Multi-objective optimization of needle roller bearings based on fatigue and wear using evolutionary algorithm," Proceedings of the Institution of Mechanical Engineers, Part J: Journal of Engineering Tribology, vol. 230, no. 2, pp. 170-185, 2016.

[21] A. Jat and R. Tiwari, "Multi-objective optimization of spherical roller bearings based on fatigue and wear using evolutionary algorithm," Journal of King Saud University-Engineering Sciences, 2018. 
[22] A. Jat and R. Tiwari, "Optimal design of spherical roller bearings based on multiple tasking operating requirements," Multidiscipline Modeling in Materials and Structures, vol. Vol. 16 No. 5, pp. pp. 967-990, 2020, doi: https://doi.org/10.1108/MMMS-07-2019-0129.

[23] M. Kalyan, R. Tiwari, and M. S. Ahmad, "Multi-objective optimization in geometric design of tapered roller bearings based on fatigue, wear and thermal considerations through genetic algorithms," Sadhana, vol. 45, no. 1, 2020.

[24] S. K. Verma and R. Tiwari, "Robust optimum design of tapered roller bearings based on maximization of fatigue life using evolutionary algorithm," Mechanism and Machine Theory, vol. 152, p. 103894, 2020.

[25] 6000 EN, Media Print, Germany, 2005. 